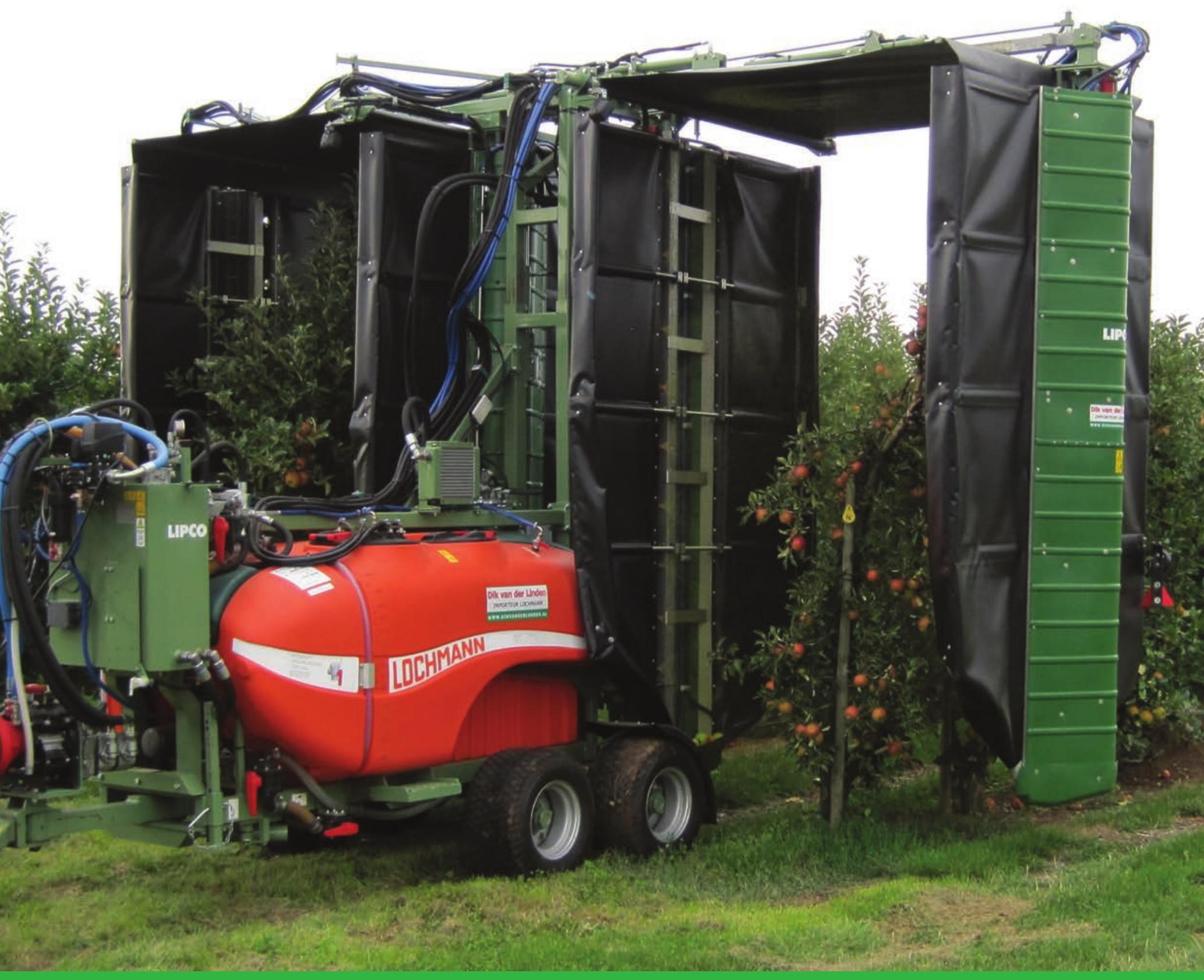

\title{
Driftreductie Lochmann tweerijen tunnelspuit
}

H. Stallinga, M. Snoussi, J.M.G.P. Michielsen, D.C. de Hoog, P. van Dalfsen, M. Wenneker \& J.C. van de Zande 



\section{Driftreductie Lochmann tweerijen tunnelspuit}

H. Stallinga, M. Snoussi, J.M.G.P. Michielsen, D.C. de Hoog, P. van Dalfsen, M. Wenneker \& J.C. van de Zande

Dit onderzoek is in samenwerking met Van der Linden Fruitteelt Machines te Dreumel en Lipco GmbH te Sasbach, Duitsland uitgevoerd door de Stichting Wageningen Research (WR), business unit Agrosysteemkunde (projectnummer 3710460700).

WR is een onderdeel van Wageningen University \& Research, samenwerkingsverband tussen Wageningen University en de Stichting Wageningen Research.

Wageningen, december 2019

Rapport WPR-880 
Stallinga, H., M. Snoussi, J.M.G.P. Michielsen, D.C. de Hoog, P. van Dalfsen, M. Wenneker \&

J.C. van de Zande, 2019. Driftreductie Lochmann tweerijen tunnelspuit. Wageningen Research, Rapport WPR-880. 36 blz.; 10 fig.; 10 tab.; 20 ref.

Dit rapport is gratis te downloaden op https://doi.org/10.18174/470899

Results of spray drift experiments are presented of the Lochmann two-row tunnel orchard sprayer in comparison with a reference spray technique for fruit crop spraying in The Netherlands. The Lochmann two-row tunnel orchard sprayer was equipped with 90\% drift reducing nozzles (Albuz TVI 8001; 7 bar spray pressure). During the spray drift experiments the downwind outside $24 \mathrm{~m}$ of an apple orchard was sprayed at the full leaf stage (BBCH 90/92) using the fluorescent tracer Acid Yellow 250. Spray drift deposition was collected downwind on a mowed grass area up till $25 \mathrm{~m}$ distance from the last tree row. Airborne spray drift was measured at $7.5 \mathrm{~m}$ distance from the last tree row on a pole at which two lines with collectors were attached at $1 \mathrm{~m}$ spacing up to $10 \mathrm{~m}$ height. For the Lochmann two-row tunnel orchard sprayer equipped with $90 \%$ drift reducing nozzles spray drift reduction at 4.5-5.5 m distance from the last tree row was $99.4 \%$ in comparison with the reference spray application. Airborne spray drift was reduced by $\mathbf{9 7 . 8 \%}$ for the Lochmann two-row tunnel orchard sprayer equipped with $90 \%$ drift reducing nozzles.

Key words: orchard sprayer, tunnel sprayer, spray drift, nozzle type, air assistance, spray drift reduction

(C) 2019 Wageningen, Stichting Wageningen Research, Wageningen Plant Research, Business unit Agrosysteemkunde, Postbus 16, 6700 AA Wageningen; T 03174807 00; www.wur.nl/plant-research

KvK: 09098104 te Arnhem

VAT NL no. 8113.83.696.B07

Stichting Wageningen Research. Alle rechten voorbehouden. Niets uit deze uitgave mag worden verveelvoudigd, opgeslagen in een geautomatiseerd gegevensbestand, of openbaar gemaakt, in enige vorm of op enige wijze, hetzij elektronisch, mechanisch, door fotokopieën, opnamen of enige andere manier zonder voorafgaande schriftelijke toestemming van Stichting Wageningen Research.

Stichting Wageningen Research is niet aansprakelijk voor eventuele schadelijke gevolgen die kunnen ontstaan bij gebruik van gegevens uit deze uitgave.

Rapport WPR-880

Foto omslag: Jan van de Zande (Lochmann-2row-tunnel-jvdz_IMG_2362.JPG) 


\section{Inhoud}

Woord vooraf $\quad 5$

$\begin{array}{ll}\text { Samenvatting } & 7\end{array}$

$\begin{array}{ll}\text { Summary } & 9\end{array}$

$1 \quad$ Inleiding $r$

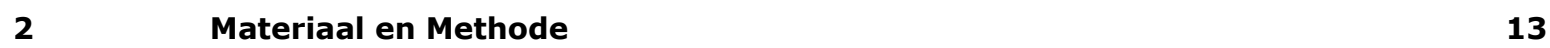

$\begin{array}{lll}2.1 & \text { Afstelling en beschrijving spuittechniek } & 13\end{array}$

2.1.1 Karakteristieken Munckhof dwarsstroomspuit $\quad 13$

2.1.2 Lochmann tweerijen tunnelspuit $\quad 13$

2.1.3 Samenvatting gebruikte spuittechnieken 16

$\begin{array}{lll}2.2 & \text { Beschrijving metingen en verwerking resultaten } & 17\end{array}$

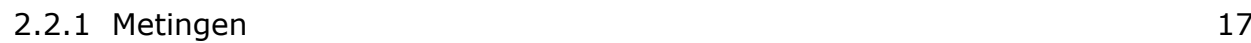

2.2.2 Analyses 18

$\begin{array}{ll}2.2 .3 \text { Berekeningen en statistiek } & 18\end{array}$

$\begin{array}{lll}2.3 \text { Weersomstandigheden } & 20\end{array}$

$3 \quad$ Resultaten $r 22$

3.1 Drift naar de grond naast het perceel $\quad 22$

$\begin{array}{lll}3.2 & \text { Drift naar de lucht } & 24\end{array}$

4 Discussie $\quad 26$

$\begin{array}{llr}5 & \text { Conclusie } & 27\end{array}$

$\begin{array}{ll}\text { Literatuur } & \mathbf{2 8}\end{array}$

$\begin{array}{lll}\text { Bijlage } 1 & \text { Script statistische analyse } & 30\end{array}$

Bijlage 2 Weersomstandigheden tijdens de driftmetingen 31

Bijlage 3 Driftdepositie (\% van afgifte) op de grond naast het gewas 32

Bijlage 4 Drift naar de lucht (\% van afgifte) 34

Bijlage 5 Ventilator snelheid van Lochman tunnelspuit 35 



\section{Woord vooraf}

Emissie van gewasbeschermingsmiddelen verminderen is van groot belang voor de fruitteelt en speelt een belangrijke rol bij de invulling van beleid en regelgeving in Nederland. Toedieningstechnieken die de drift, het verwaaien van de spuitvloeistof tot buiten het doelgewas, reduceren zijn nodig om de beleidsdoelen te kunnen realiseren en om gewasbeschermingsmiddelen veilig te kunnen gebruiken. In deze rapportage wordt het onderzoek van een driftreducerende techniek in de fruitteelt beschreven. Driftonderzoek is gedaan aan de Lochmann tweerijen tunnelspuit uitgerust met $90 \%$ driftreducerende spuitdoppen, in het volbladstadium van een appelboomgaard. De driftmetingen zijn uitgevoerd in het emissie proefveld voor de fruitteelt, een boomgaard van WUR op de Proeftuin Randwijk, met medewerking van de Proeftuin en WUR Unifarm.

Dit onderzoek is uitgevoerd in samenwerking met Van der Linden Fruitteelt Machines (Dreumel) en Lipco GmbH (Sasbach, Duitsland) en begeleid door dhr. R. van der Linden.

Wageningen, februari 2019 


\section{Samenvatting}

Uit eerdere driftmetingen is gebleken dat tunnelspuiten uitgerust met standaard spuitdoppen een driftreductie van $85 \%$ kunnen realiseren. Door het tegen elkaar in blazen en spuiten wordt bij de individuele boomrijen meer spuitvloeistof in de bomen 'gevangen' en door de afscherming door de tunnel waaronder gespoten wordt kan er minder spuitvloeistof wegwaaien. Naar verwachting zal ook de Lochmann tweerijentunnelspuit een hoge driftreductie geven. Zeker als deze uitgerust wordt met $90 \%$ driftreducerende spuitdoppen (DRD90). Om deze verwachting te toetsen en onderbouwen is door WUR in samenwerking met Van der Linden Fruitteelt Machines en Lipco GmbH driftonderzoek uitgevoerd. In het veldonderzoek werd een vergelijking gemaakt tussen de spuitdrift van de Lochmann tweerijentunnelspuit uitgerust met 90\% driftreducerende doppen (Albuz TVI8001, 7 bar; DRD90) en een standaard dwarsstroom boomgaardspuit (Munckhof met Albuz ATR Lila doppen). De driftmetingen werden dusdanig opgezet dat de resultaten voldoen aan de opgestelde eisen vanuit de toelating van gewasbeschermingsmiddelen (Ctgb), het Activiteitenbesluit Milieubeheer en internationale afspraken rondom meten en classificeren van drift (ISO22866, ISO22369).

De driftmetingen werden uitgevoerd door de buitenste $24 \mathrm{~m}$ ( 8 boomrijen) aan de benedenwindse zijde van een appelboomgaard in het volblad stadium (BBCH 90/92) te bespuiten met de fluorescerende tracer Acid Yellow 250. De driftdepositie werd op een gemaaide grasstrook gemeten naast het bespoten perceel tot op $25 \mathrm{~m}$ afstand vanaf de buitenste bomenrij. De gebruikte collectoren waren filterdoeken (Technofil TF-290) van 0,50x0,10 m die aaneengesloten lagen van $3 \mathrm{~m}$ tot $15 \mathrm{~m}$ en filterdoeken van $1,00 \times 0,10 \mathrm{~m}$ op $20 \mathrm{~m}$ en $25 \mathrm{~m}$ van de laatste bomenrij. De drift naar de lucht werd gemeten op 7,5 $\mathrm{m}$ van de laatste bomenrij met behulp van een mast tot $10 \mathrm{~m}$ hoogte met op elke meter hoogte een driftbolcollector (Siral Abdriftkollektoren).

Bij driftmetingen tijdens bespuitingen van een appelboomgaard in het volblad stadium (BBCH 90/92) met de Lochmann tweerijen tunnelspuit met TVI8001 spuitdoppen (7 bar; DRD90) werd in vergelijking met een referentie boomgaard bespuiting bij een $3 \mathrm{~m}$ teeltvrije zone op de strook 41/2-51/2 $\mathrm{m}$ vanaf de buitenste bomenrij een driftreductie gevonden van 99,4\%. Op grond van dit resultaat kan de Lochmann tweerijen tunnelspuit met DRD90 spuitdoppen in de driftreducerende techniek klasse DRT99 ingedeeld worden.

Bij de drift naar de lucht, gemiddeld over 0-10 m hoogte op 7,5 m van de buitenste bomenrij, geeft de Lochmann tweerijen tunnelspuit met TVI8001 spuitdoppen (DRD90) een driftreductie van 97,8\%. 


\section{Summary}

Earlier spray drift experiments showed that orchard tunnel sprayers equipped with standard nozzles achieved a spray drift reduction of $85 \%$. Spraying and blowing from both sides at the same time towards the tree canopy captures higher levels of spray in canopy and by shielding the spray process with a tunnel less spray can blow away. It is therefore expected that also the Lochmann two-row tunnel orchard sprayer may achieve high levels of spray drift reduction. To assess and underpin this expectation WUR performed spray drift field experiments in cooperation with Van der Linden Fruitteelt Machines and Lipco $\mathrm{GmbH}$. In the spray drift field experiments a comparison was made between the Lochmann two-row tunnel orchard sprayer fitted with 90\% drift reducing nozzles (Albuz TVI8001; 7 bar spray pressure, DRN90) and a standard cross-flow fan orchard sprayer - Munckhof with Albuz ATR Lilac nozzles. Spray drift experiments were setup to fulfil the requirements to provide proper data for the authorisation procedure of Plant Protection Products (Ctgb), the Environmental Decree (TCT protocol) and international protocols on spray drift measurements and its classification (ISO22866, ISO22369).

During the spray drift experiments the downwind outside $24 \mathrm{~m}$ of an apple orchard was sprayed at the full leaf stage (BBCH 90/92) using the fluorescent tracer Acid Yellow 250. Spray drift deposition was collected downwind on a mowed grass area up till $25 \mathrm{~m}$ distance from the last tree row. Filter collectors were used (Technofil TF-290) on ground surface of sizes $0.50 \times 0.10 \mathrm{~m}$ in a continuous row from $3 \mathrm{~m}$ to $15 \mathrm{~m}$ and of $1.00 \times 0.10 \mathrm{~m}$ at $20 \mathrm{~m}$ and $25 \mathrm{~m}$ distance from the last tree row. Airborne spray drift was measured at $7.5 \mathrm{~m}$ distance from the last tree row on a pole at which two lines with collectors (Siral Abdriftkollektoren) were attached at $1 \mathrm{~m}$ spacing up to $10 \mathrm{~m}$ height.

The spray drift experiments showed that spraying an apple orchard at the full leaf stage (BBCH 90/92) with a Lochmann two-row tunnel orchard sprayer fitted with 90\% drift reducing nozzles (Albuz TVI8001; 7 bar spray pressure, DRN90) spray drift reduction at 4.5-5.5 $\mathrm{m}$ distance from the last tree row was $99.4 \%$ in comparison with the reference spray application. Based on these results this combination can be classified as a spray Drift Reducing Technology (DRT) in the $99 \%$ reduction class.

Airborne spray drift reduction at $7.5 \mathrm{~m}$ distance from the last tree row averaged over $10 \mathrm{~m}$ height was for the Lochmann two-row tunnel orchard sprayer fitted with $90 \%$ drift reducing nozzles (Albuz TVI8001; 7 bar spray pressure, DRN90) 97.8\%. 


\section{$1 \quad$ Inleiding}

De emissie van gewasbeschermingsmiddelen verminderen is van groot belang voor de fruitteelt (VW et al., 2007) en speelt een belangrijke rol bij de invulling van Duurzame Gewasbescherming (EZ, 2013), het Activiteitenbesluit Milieubeheer (I\&W, 2017) en de toelating van gewasbeschermingsmiddelen (Ctgb, 2018). Doel van de Nota Duurzame Gewasbescherming (EZ, 2013) is verminderen van de overschrijding van de milieukwaliteitsnormen voor gewasbeschermingsmiddelen in oppervlaktewater tot nagenoeg nul. Hierbij moet het aantal overschrijdingen van de milieukwaliteitsnormen voor gewasbeschermingsmiddelen in oppervlaktewater in 2023 met 90\% afgenomen zijn ten opzichte van die in 2013. Om dit te realiseren moet op alle percelen de toediening van gewasbeschermingsmiddelen met minimaal $75 \%$ driftreducerende technieken (DRT) uitgevoerd worden. Hierbij stelt het Activiteitenbesluit Milieubeheer (I\&W, 2017) dat voor de fruitteelt de teelvrije zone bij een DRT75 minimaal 4,5 m moet zijn. Als een $3 \mathrm{~m}$ teelvrije teeltvrije zone gebruikt wordt moeten gewasbeschermingsmiddelen met een minimaal $90 \%$ driftreducerende techniek (DRT90) uitgevoerd worden.

Daarnaast is ook bij de toelating van gewasbeschermingsmiddelen de driftdepositie op wateroppervlak van belang. Het College voor de Toelating van Bestrijdingsmiddelen en Biociden (Ctgb) neemt beslissingen, onder andere op basis van de inschatting van de effecten op het milieu (Ctgb, 2018). Hierbij is het nodig te weten hoeveel van het middel in het oppervlaktewater terecht komt. Het Ctgb heeft de resultaten van emissie-onderzoek (Zande et al., 2018) ingedeeld naar driftreducerende techniek klassen (DRT) opgenomen in een drifttabel (Ctgb, 2018). In tabel 1.1 is voor de DRT klassen DRT75 tot DRT99 zoals gebruikt in de fruitteelt voor de kale boom situatie (voor 1 mei) en de volblad situatie (na 1 mei tot 50\% bladval) in driftdepositie weergegeven bij een teeltvrije zone van $3 \mathrm{~m}$.

Tabel 1.1 Driftdepositie (\% van uitgebracht spuitvolume per oppervlakte eenheid) op wateroppervlak (3 $m$ teeltvrije zone, 4,5-5,5 m vanaf buitenste bomenrij) van driftreducerende technieken (DRT) in verschillende klassen in de kale boom (voor 1 mei) en de volblad (na 1 mei) situatie (naar: Ctgb, 2018).

\begin{tabular}{lrr} 
Driftreducerende techniek groot fruit & Driftpercentage [\%] & kaal \\
\cline { 2 - 3 } Standaard & 16,6 & 8,6 \\
\hline DRT75: & 8,3 & 2,0 \\
\hline DRT90: & 2,5 & 1,0 \\
\hline DRT95: & 1,3 & 0,36 \\
\hline DRT97,5: & 1,3 & 0,13 \\
\hline DRT99: & 0,3 & 0,65 \\
\hline
\end{tabular}

De emissie van gewasbeschermingsmiddelen in de fruitteelt is hoog ten opzichte van andere teeltsectoren. Dit wordt onder meer veroorzaakt door de opgaande en horizontale spuitrichting en de vaak krachtige luchtondersteuning bij fruitteeltspuiten waardoor veel spuitvloeistof door het bladerdek van de bomenrijen heen gespoten wordt. Om drift te beperken zijn verschillende techniek- en teeltmaatregelen mogelijk. Technische maatregelen kunnen bestaan uit doptype, afscherming en luchtondersteuning. Een teeltmaatregel is bijvoorbeeld het aanleggen van een windsingel (windhaag), of het aanleggen van een teeltvrije zone waardoor de afstand tussen het te bespuiten gewas en het oppervlaktewater vergroot wordt, en de drift naar het wateroppervlak af zal nemen. Emissie naar de lucht (druppels en damp) bij gewasbespuitingen wordt in de toelating van middelen of het Activiteitenbesluit Milieubeheer momenteel niet in ogenschouw genomen. Uit metingen is gebleken dat bespuitingen met neveldoppen een aanzienlijke drift naar de lucht tot gevolg kunnen hebben (Michielsen et al., 2007, Zande et al., 2014). Deze emissie kan relevant zijn voor milieubelasting op grotere afstand van percelen, of consequenties hebben voor de aanwezigheid van bijvoorbeeld omwonenden en bebouwing (Gezondheidsraad, 2014).

Door fruittelers is aangegeven dat het eenzijdig spuiten van de buitenste bomenrij bezwaren heeft in verband met de effectiviteit van de middelen en de bladbedekking van de bespuiting. Men geeft de 
voorkeur aan de buitenste bomenrij van twee zijden te bespuiten. Door gebruik te maken van een tunnelspuit (Porskamp et al., 1994a, 1994b; Huijsmans et al., 1993) is aangetoond dat dit kan en een driftreductie van 85\% gehaald werd (Huijsmans et al., 1997; DRT75, TCT, 2018a). In de tussentijd zijn nieuwe uitvoeringsvormen van tunnelspuiten op de markt gekomen. Van de combinatie tunnelspuit en 90\% driftreducerende spuitdoppen (DRD90) wordt verwacht dat zij een aanzienlijk hogere driftreductie kan halen dan de eerdere metingen met standaard spuitdoppen in de tunnelspuit. Door het ontwerp van tweerijen tunnelspuiten, die symmetrisch achter de trekker lopen, zijn belangrijke bezwaren van inzetbaarheid en capaciteit opgelost. Hierdoor, en door de verbeterde depositie in de boom (13\%-45\%; Wenneker et al., 2018) en verwacht lager middel gebruik door opvangen en recycling van spuitvloeistof in de tunnel (30\%-60\%; Huijsmans et al., 1993) is er opnieuw belangstelling ontstaan voor tunnelspuiten. Om de verwachte hoge driftreductie van de Lochmann tweerijen tunnelspuit te onderbouwen is dit driftonderzoek in opdracht van Van der Linden Fruitteelt Machines (Dreumel) en Lipco GmbH (Sasbach Duitsland) uitgevoerd.

\section{Doel van het onderzoek}

Het doel van het onderzoek is de vergelijking van de spuitdrift van de Lochmann tweerijen tunnelspuit met $90 \%$ driftreducerende doppen en een standaard dwarsstroom boomgaardspuit (met ATR Lila spuitdoppen). De driftmetingen werden dusdanig opgezet dat de resultaten voldoen aan de opgestelde eisen vanuit de toelating van gewasbeschermingsmiddelen (Ctgb), het Activiteitenbesluit Milieubeheer (I\&W, 2017) en internationale afspraken rondom erkenning van driftmetingen (ISO22866, 2005; ISO22369, 2006). In deze rapportage worden de uitgevoerde driftmetingen van de Lochmann tweerijen en de standaard dwarsstroom boomgaardspuit (Huijsmans et al., 1997) tijdens bespuitingen van een appelboomgaard in het volblad (na $1 \mathrm{mei}$ ) stadium beschreven. In hoofdstuk 2 wordt de proefopzet besproken, daarna volgen in hoofdstuk 3, 4 en 5 respectievelijk de resultaten, discussie en conclusies. 


\section{Materiaal en Methode}

\subsection{Afstelling en beschrijving spuittechniek}

In een veldonderzoek is in 2018 de drift vastgelegd van een Lochmann tweerijen tunnelspuit (Lochmann Plantatec, Nals Italië), in Nederland vertegenwoordigd door Van der Linden Fruitteelt Machines te Dreumel. De driftmetingen zijn uitgevoerd met een Albuz TVI8001 spuitdop bij 7 bar spuitdruk (90\% driftreducerend; DRD90, TCT, 2018b) en bij 330 rpm aftakas toerental. Dit verlaagde aftakas toerental is ingesteld om bij de machine die voor het onderzoek ter beschikking was een lager niveau van luchthoeveelheid te realiseren overeenkomstig de maximale luchthoeveelheid van de tunnelspuiten die op de Nederlandse markt verkocht worden.

De drift van de Lochmann tweerijen tunnelspuit werd vergeleken met die van de Munckhof dwarsstroomspuit voorzien van Albuz ATR Lila doppen (referentietechniek; TCT, 2017b). In paragraaf 2.1.1 staan karakteristieken beschreven van de in de proeven gebruikte Munckhof dwarsstroomspuit en in paragraaf 2.1.2 staat een beschrijving van de Lochmann tweerijen tunnelspuit. In paragraaf 2.1.3 staat een samenvattend overzicht van de gebruikte spuittechnieken.

\subsubsection{Karakteristieken Munckhof dwarsstroomspuit}

De Munckhof dwarsstroomspuit (Munckhof, Horst) is een axiaalspuit voorzien van een dwarsstroomkap op de ventilator (figuur 2.1).

In tabel 2.1 staan de posities van de dophouders van de Munckhof dwarsstroomspuit boven grondoppervlak weergegeven.

Tabel 2.1 Dophoogte vanaf de grond [cm] van de dophouders op de Munckhof dwarsstroomspuit.

\begin{tabular}{lrrrrrrrrrrr} 
Dopnr & 1 & 2 & 3 & 4 & 5 & 6 & 7 & 8 & 9 \\
links & 50 & 68 & 84 & 99 & 120 & 153 & 180 & 215 & 250 & 285 \\
\hline rechts & 48 & 66 & 81 & 99 & 121 & 153 & 181 & 216 & 251 & 286 \\
\hline
\end{tabular}

Er werd gespoten met $2 \times 8$ geopende spuitdoppen, waarbij de onderste $(50 \mathrm{~cm})$ en de bovenste dop (op $285 \mathrm{~cm}$ ) waren gesloten. De bovenste spuitende dop zat op 2,50 m hoogte in overeenstemming met de toppen van de fruitbomen. De spuit werd aangedreven door een New Holland T4050N fruitteelt trekker, met een rijsnelheid van $6,7 \mathrm{~km} / \mathrm{h}$ en een aftakas toerental van $540 \mathrm{rpm}$.

Er werd gemeten bij de vollucht stand van de ventilator, hierbij was de gemiddelde luchtsnelheid over de gehele luchtspleet $21 \mathrm{~m} / \mathrm{s}$. Bij de bespuitingen werd de drift vastgelegd bij gebruik van Albuz ATR Lila werveldoppen en een druk van 7 bar (referentie) en een spuitvolume van 226 L/ha.

\subsubsection{Lochmann tweerijen tunnelspuit}

In tabel 2.2 staan de posities van de dophouders op de Lochmann tweerijen tunnelspuit boven grondoppervlak weergegeven.

Tabel 2.2 Dophoogte vanaf de grond [ $\mathrm{cm}]$ van de dophouders links en rechts op de vier spuitelementen van de Lochmann tweerijen tunnelspuit.

\begin{tabular}{|c|c|c|c|c|c|c|c|c|c|c|}
\hline Dopnr & 1 & 2 & 3 & 4 & 5 & 6 & 7 & 8 & 9 & 10 \\
\hline links+rechts & 36 & 60 & 84 & 108 & 136 & 164 & 192 & 220 & 255 & 290 \\
\hline
\end{tabular}




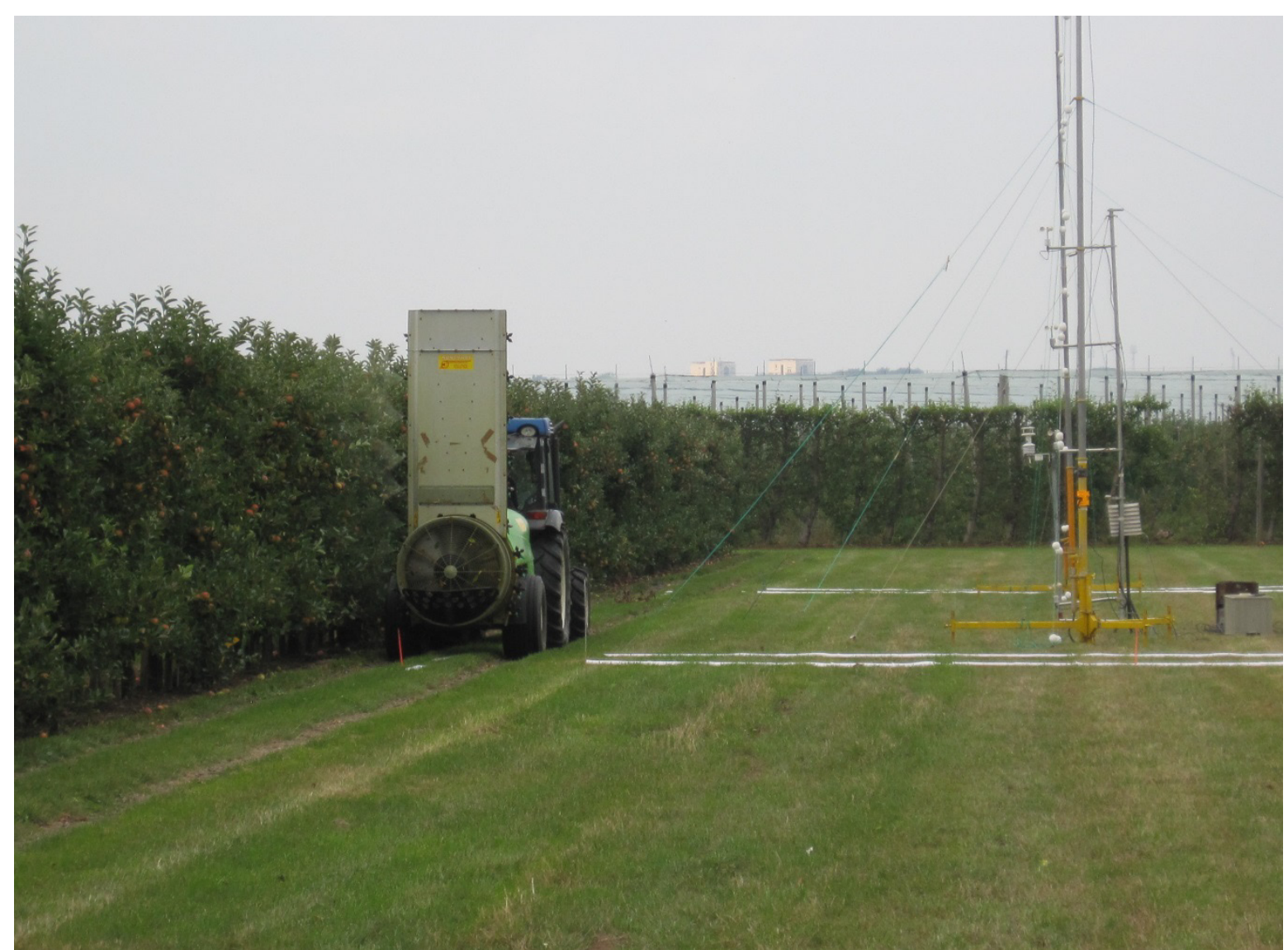

Figuur 2.1 Standaard dwarsstroomspuit (Munckhof) tijdens driftmetingen; bespuiting buitenste werkgang bij drift meetstrook.

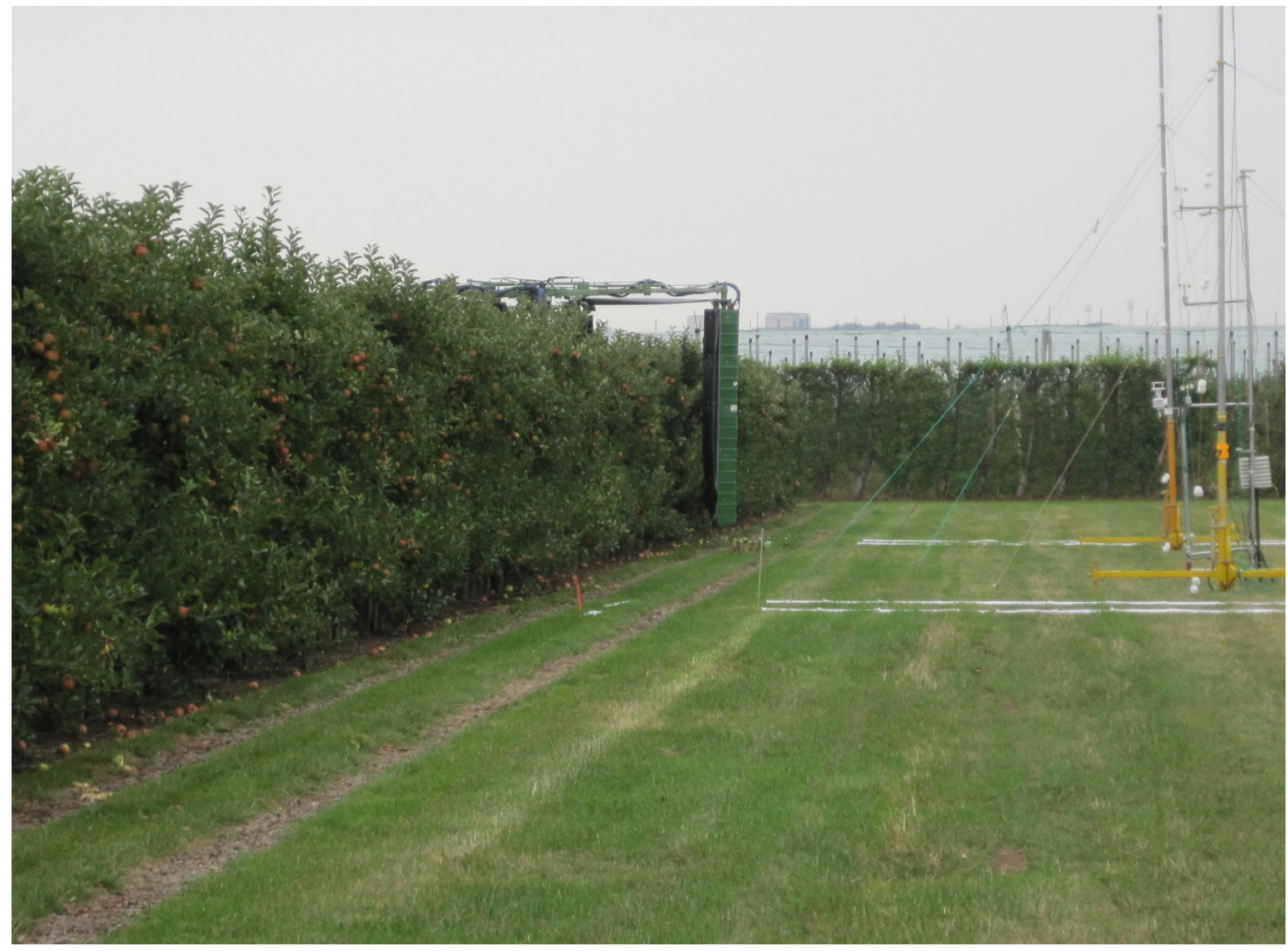

Figuur 2.2 Lochmann tweerijen tunnelspuit tijdens driftmetingen; bespuiting buitenste werkgang bij drift meetstrook. 
Tijdens de driftmetingen (figuur 2.2) werd er gespoten met $2 \times 2 \times 9$ geopende spuitdoppen. De bovenste spuitende dop zat op 2,55 m hoogte in overeenstemming met de toppen van de fruitbomen. De spuit werd getrokken door een New Holland T4050N fruitteelt trekker. De rijsnelheid, bij een aftakas toerental van $330 \mathrm{rpm}$, was gemiddeld over alle metingen $6,9 \mathrm{~km} / \mathrm{h}$. Bij de bespuitingen werd de drift vastgelegd bij gebruik van Albuz TVI8001 spuitdop bij 7 bar spuitdruk (figuur 2.3; DRD90, TCT, 2018b). Op basis van de gemeten rijsnelheid en dopafgifte was het uitgebrachte spuitvolume gemiddeld over alle metingen $318 \mathrm{~L} / \mathrm{ha}$.
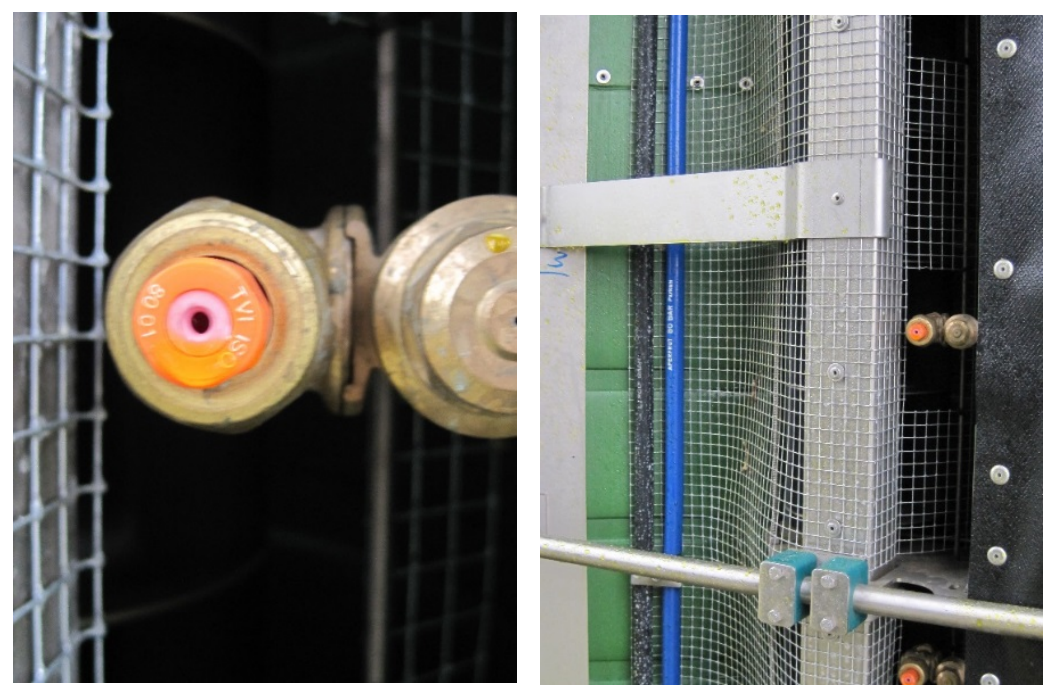

Figuur 2.390\% driftreducerende Albuz TVI8001 spuitdop (links) aan de binnenzijde van de tunnel in de ventilator uitstroomopening (rechts) op de Lochmann tweerijen tunnelspuit.

De tunnelconstructie (Lipco) bestaat uit een automatisch strak gespannen scherm aan de bovenzijde van $1,80 \mathrm{~m}$ lengte. De maximale binnenhoogte van de tunnel is 3,5 $\mathrm{m}$ en is aangepast aan de maximale boomhoogte (figuur 2.4). Aan weerszijden van de bomenrij hangt een ventilatorkast met twee tangentiaal ventilatoren boven elkaar. De luchtinlaat vanuit de tunnel is afgeschermd met gaas (figuur 2.3). In de verzonken uitstroomopening van de ventilator zit de vloeistofbuis met daarop 10 spuitdoppen (figuur 2.3) op verschillende afstanden van elkaar (tabel 2.2). Aan de voor en achterzijde van de ventilatorkast zit een vaste constructie met een scherm van $2.0 \mathrm{~m}$ lengte in de rijrichting en langs de bomenrij (figuur 2.4). De tunnel werd in de breedte zo ingesteld dat de tunnel net buiten de bladeren van de bomen loopt (figuur 2.4, figuur 2.5).
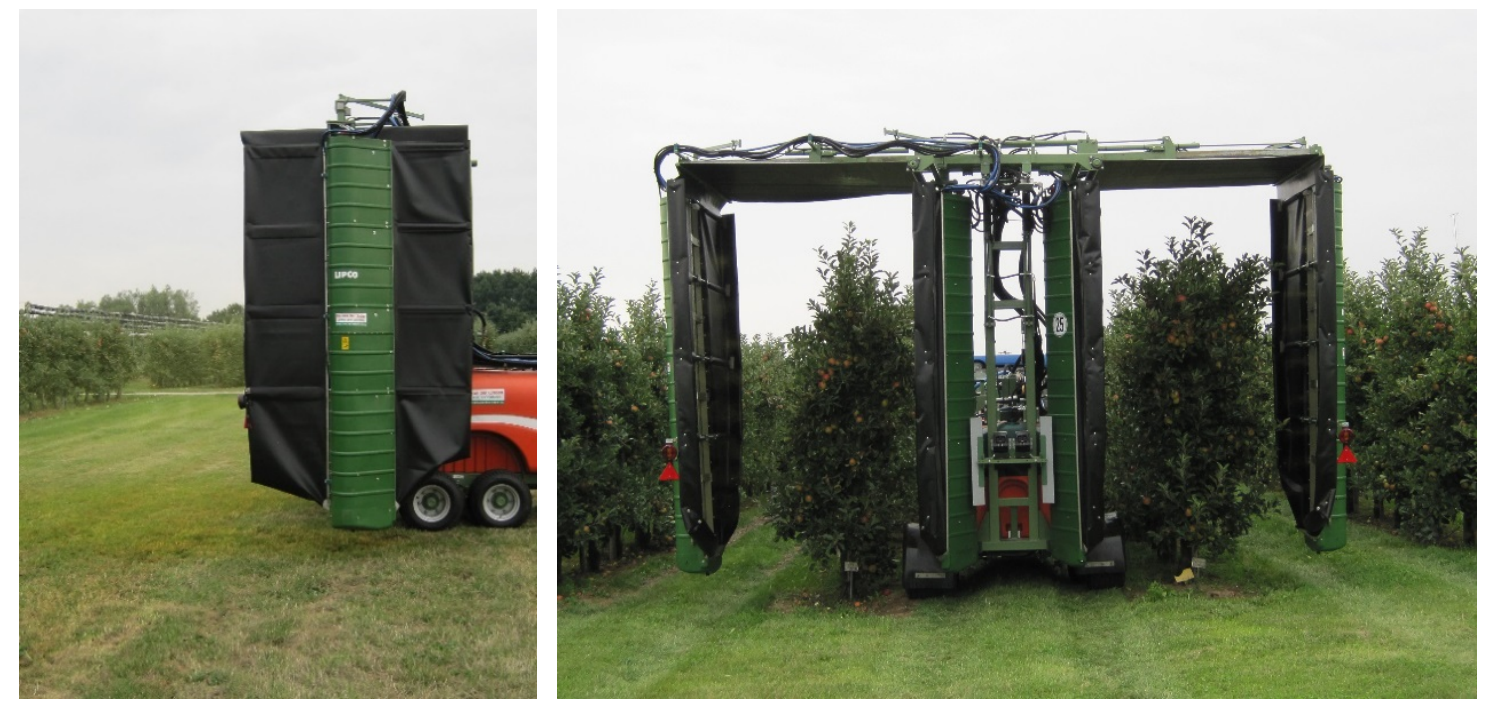

Figuur 2.4 Lochmann tweerijen tunnelspuit in boomgaard; zijaanzicht en achteraanzicht. 
Gemeten over de gehele luchtuitstroomopening van de tangentiaal ventilator was de gemiddelde uittreesnelheid van de lucht $10 \mathrm{~m} / \mathrm{s}$. Bij de in de driftmetingen gebruikte tunnelspuit was dit bij $330 \mathrm{rpm}$ aftakas toerental. Bij machines die op de markt zijn is deze luchtopbrengst bij maximale luchtinstelling (500-540 rpm). Een vergelijking tussen de ventilator toerentallen van de in de driftmetingen gebruikte machine en een machine van een teler bij verschillende aftakas toerentallen staat in bijlage 5 . Hieruit blijkt dat bij een aftakas toerental van $330 \mathrm{rpm}$ van de tunnelspuit gebruikt in de driftmetingen het toerental van de tangentiaal ventilatoren (1570 rpm) gelijk is als bij 500-540 rpm aftakas toeren van de praktijk spuit. De 'lage' luchtinstelling van de Lochmann tweerijen tunnelspuit gebruikt in de driftmetingen komt dus overeen met de standaard maximale luchtinstelling (500-540 rpm) van deze machines die in de praktijk gebruikt worden.

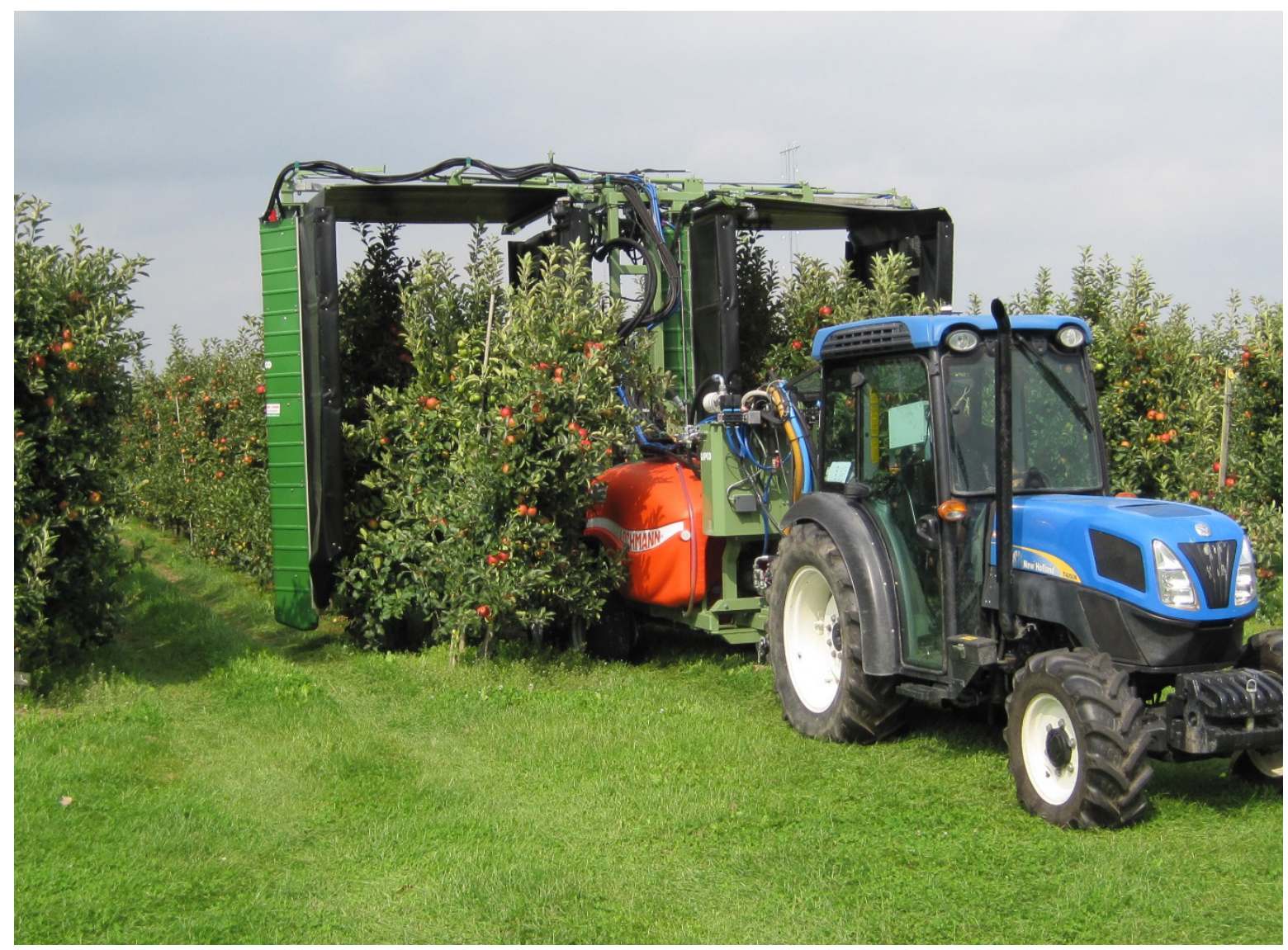

Figuur 2.5 Lochmann tweerijen tunnelspuit tijdens driftmetingen (vooraanzicht).

\subsubsection{Samenvatting gebruikte spuittechnieken}

In tabel 2.3 staat een samenvatting van de tijdens de driftmetingen gebruikte spuittechnieken.

Tabel 2.3 Samenvatting gebruikte spuittechnieken in de driftmetingen.

\begin{tabular}{lcc}
\hline Spuit & Munckhof dwarsstroom & Lochmann tweerijen tunnelspuit \\
aftakas & 540 & 330 \\
\hline Spuitdoppen & Albuz & Albuz \\
\hline & ATR Lila & TVI8001 \\
\hline doptype & Werveldop & DRD90 \\
\hline druk [bar] & 7 & 7 \\
\hline n-doppen & $2 \times 8$ & $2 \times 2 \times 9$ \\
\hline dop afgifte $[\mathrm{l} / \mathrm{min}]$ & 0,42 & 0,61 \\
\hline Gemiddelde rijsnelheid $[\mathrm{km} / \mathrm{h}]$ & 6,7 & 6,9 \\
\hline Gemiddeld spuitvolume $[\mathrm{L} / \mathrm{ha}]$ & 226 & 318
\end{tabular}




\subsection{Beschrijving metingen en verwerking resultaten}

\subsubsection{Metingen}

De experimenten werden op 15 augustus, 23 augustus, 19 oktober, 13 november en 21 november 2018 uitgevoerd op de Proeftuin Randwijk te Randwijk. Op perceel Oost $1 \mathrm{~A}$ werden de driftmetingen in overeenstemming met de driftmeetprotocollen (TCT 2017b, ISO22866) uitgevoerd. Dit perceel is aangeplant met het appelras Elstar. De fruitbomen staan in een plantverband van $1,10 \mathrm{~m}$ afstand in de rij en $3 \mathrm{~m}$ tussen de rijen (rijafstand). De bomen waren 2,75 $\mathrm{m}$ hoog en in het volblad stadium (BBCH 90/92). Het perceel bestond uit een blok van 110 meter lengte en 14 rijen (52 m) breed (figuur 2.6). Daaromheen lag een strook gras van ongeveer $30 \mathrm{~m}$ breed. Op deze strook gras werden aan de benedenwindse zijde van de boomgaard twee driftmeetstroken uitgelegd (figuur 2.6). Tijdens de driftmetingen werden de laatste acht bomenrijen $(24 \mathrm{~m}$ ) aan de benedenwindse zijde volledig bespoten. Met één en dezelfde instelling werd steeds het blok van acht boomrijen bespoten.

Bij elke driftmeetstrook werden twee meetraaien (duplo bepalingen) uitgelegd met 1 meter tussenruimte tussen de meetraaien. In het meetgedeelte naast het perceel werden 2 herhalingen van de driftmeetstroken achter elkaar gelegd, op een onderlinge afstand van $30 \mathrm{~m}$.

Op de volgende posities werden collectoren (Technofil TF $290 ; 10 \times 100 \mathrm{~cm}, 10 \times 50 \mathrm{~cm}$ ) gelegd om de driftdepositie naar de grond te meten (figuur 2.6, figuur 2.7):

- Op 1,5 meter, evenwijdig aan de buitenste bomenrij, een collector van 1 meter lengte.

- Op 3 - 15 meter aaneengesloten collectoren van 0,5 meter (haaks op de bomenrij).

- Op 20 en 25 meter een collector van 1 meter (haaks op de bomenrij).

De afstand werd gemeten vanaf het midden (hart) van de buitenste bomenrij.

De emissie naar de lucht werd op 7,5 m vanaf de laatste bomenrij met behulp van een mast van $10 \mathrm{~m}$ hoogte gemeten (figuur 2.7), met in twee lijnen met ieder op elke meter hoogte een driftbolcollector (Siral Abdriftkollektoren art. nr. 00131).

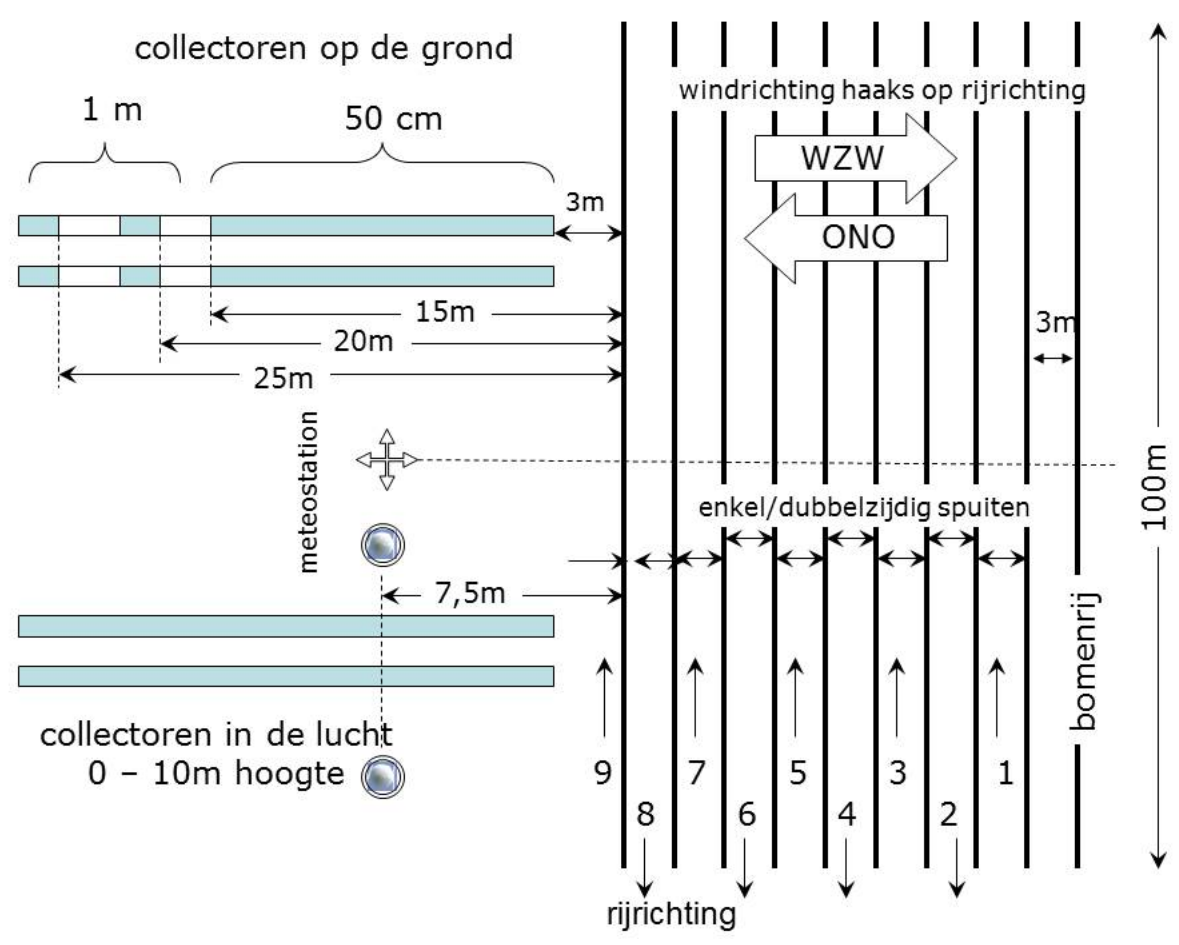

Figuur 2.6 Schematische weergave proefveld en meetopstelling. 


\subsubsection{Analyses}

De bespuitingen werden uitgevoerd met water waaraan Acid Yellow 250 (AY250, DC Fine Chemicals, CAS nummer 93859-32-6, 2-5 g/L) en een niet-ionische uitvloeier (Agral Gold, 0,075 mL/L) was toegevoegd. Na de bespuiting werden de collectoren verzameld en gecodeerd voor verdere analyse op de hoeveelheid AY250. Elke meetdag werden uit een spuitende spuitdop ook monsters van de tankvloeistof genomen om de AY250-concentratie van de verspoten spuitvloeistof te meten. In het laboratorium werden de collectoren met gedemineraliseerd water gespoeld, zodanig dat de AY250 op de collectoren in oplossing kwam. Van deze oplossing werd de concentratie aan AY250 gemeten met behulp van een fluorimeter (Perkin Elmer LS $55 ; \lambda_{e x}=450 \mathrm{~nm} ; \lambda_{\mathrm{em}}=500 \mathrm{~nm}$ ). Voor het bepalen van de achtergrondfluorescentie werden blanco collectoren geanalyseerd. De concentratie AY250 in de tankmonsters werd ook fluorimetrisch bepaald. De afbraak in zonlicht van de AY250 op de collectoren werd apart bepaald. Gezien de beperkte blootstellingsduur aan zonlicht van de collectoren tijdens de driftmetingen in het veld ( $<30$ minuten) was het niet nodig voor afbraak door zonlicht te corrigeren.

\subsubsection{Berekeningen en statistiek}

De concentratie werd omgerekend naar volume spuitvloeistof per oppervlakte-eenheid. Het percentage drift is berekend door de driftdepositie per oppervlakte-eenheid uit te drukken in procenten van de door de spuitdoppen in het perceel verspoten hoeveelheid vloeistof per oppervlakte-eenheid.

De gemeten fluorescentiewaarde werd omgerekend naar de driftdepositie $\left(\mu \mathrm{l} / \mathrm{cm}^{2}\right)$ volgens:

$$
D_{\text {monster }}=\frac{\left(F_{\text {monster }}-F_{\text {demi }}-F_{\text {blanco }}\right) \times f_{i j k} \times V_{\text {spoel }}}{C_{\text {tm }} \times A_{\text {monster }}}
$$

$\mathrm{D}=$ depositie in $\mu \mathrm{l} / \mathrm{cm}^{2}$.;

$\mathrm{F}=$ fluorescentiewaarde $; F_{\text {monster }}=$ fluorescentiewaarde van het monster $; F_{\text {demi }}=$ fluorescentiewaarde van demiwater; $F_{\text {blanco }}=$ bijdrage van de achtergrond door collector;

$\mathrm{f}_{\mathrm{ijk}}=\mathrm{ijkfactor} ; \mathrm{V}_{\text {spoel }}=$ extractievolume in liter;

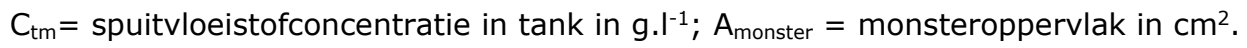

Voor de statistische verwerking wordt indien $\left(F_{\text {monster }}-F_{\text {demi }}-F_{\text {blanco }}\right)$ kleiner of gelijk aan 0 is, hier een kleine waarde ingevuld $(0,001)$.

Vervolgens werd per monster de driftdepositie uitgedrukt als percentage van het uitgebracht spuitvolume volgens:

$$
P=\frac{D_{m}}{Q / 100} \times 100 \%
$$

$P=$ percentage drift van het uitgebrachte spuitvolume; $D_{m}=$ driftdepositie in $\mu \mathrm{l} / \mathrm{cm}^{2}$;

$\mathrm{Q}=$ spuitvolume in $\mathrm{l} / \mathrm{ha}$

Voor de vergelijking van de driftdepositie van de verschillende spuittechnieken zijn de driftwaarden (\% van spuitvolume) uitgerekend voor verschillende evaluatiestroken overeenkomend met de positie van de sloot (insteek-insteek afstand $4 \mathrm{~m}$ ) en het wateroppervlak daarbinnen $(1 \mathrm{~m})$. De teeltvrije zone wordt in het Activiteitenbesluit Milieubeheer (I\&W, 2017) gedefinieerd als de afstand tussen de insteek van de sloot en de buitenste gewasrij (voor fruitteelt $3 \mathrm{~m}$ in figuur 2.8 ).

De volgende evaluatiestroken worden onderscheiden:

- slootoppervlak: 3-7, 41/2-81/2, 6-10 en 9-13 m, bij respectievelijk 3, 41/2, 6 en 9 m teeltvrije zone.

- wateroppervlak: $4 \frac{1}{2}-51 \frac{1}{2}, 6-7,71 \frac{1}{2}-81 \frac{1}{2}, 101 \frac{1}{2}-11 \frac{1}{2} \mathrm{~m}$, bij respectievelijk 3, 41/2, 6 en $9 \mathrm{~m}$ teeltvrije zone.

- naar de lucht: gemiddeld over $10 \mathrm{~m}$ hoogte op 7,5 m vanaf de laatste bomenrij. 


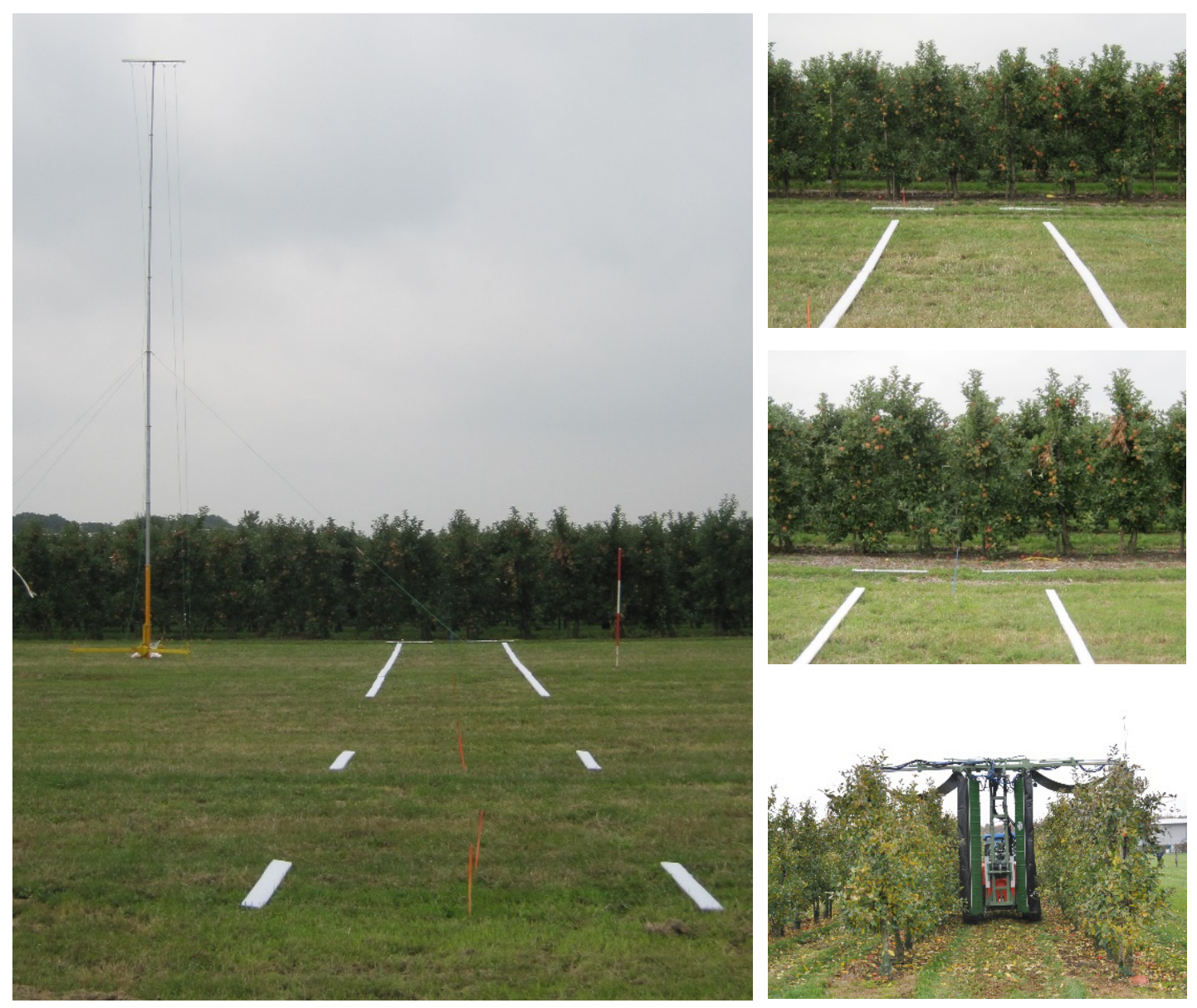

Figuur 2.7 Overzicht drift meetopstelling (links); collectoren op de grond tot $25 \mathrm{~m}$ van de buitenste bomenrij, op 7,5 $\mathrm{m}$ mast voor meten van de luchtdrift tot $10 \mathrm{~m}$ hoog; indruk van bladmassa appelbomen op de verschillende meetdagen en collectoren dicht bij buitenste bomenrij op twee meetplekken (rechts).

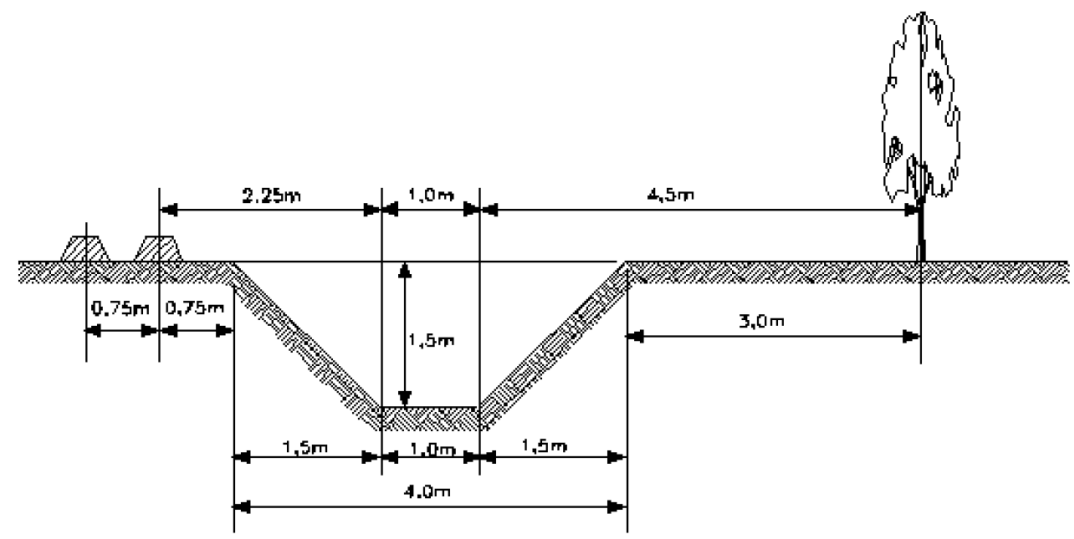

Figuur 2.8 Schematische weergave van de plaats van de sloot, het talud en het wateroppervlak ten opzichte van de laatste gewasrij in aardappelen (links) en de buitenste bomenrij in de fruitteelt (rechts) (Huijsmans et al., 1997).

De gekozen zones van 3 m, 41/2 m, 6 m en $9 \mathrm{~m}$ komen overeen met in het Activiteitenbesluit Milieubeheer (I\&W, 2017) genoemde zones. Daarbij is 4,5 $\mathrm{m}$ de teeltvrije zone waarbij een bespuiting nog met een $75 \%$ driftreducerende spuittechniek (DRT75) uitgevoerd mag worden. De zone $3 \mathrm{~m}$ geldt als teeltvrije zone als de bespuiting uitgevoerd wordt met een $90 \%$ driftbeperkende techniek (DRT90). Voor de kopakker geldt een minimale teeltvrije zone van $6 \mathrm{~m}$. 
De verschillen in driftdepositiewaarden op de evaluatiestroken tussen de verschillende spuittechnieken werden getoetst bij een onbetrouwbaarheidsdrempel van $5 \%$. Statistische analyse vond plaats met behulp van het statistische programma Genstat (Genstat Release 9.2, Payne et al., 2006). Bij de statistische analyse werd gebruik gemaakt van de Genstat procedure IRREML (Keen en Engel, 1998). In bijlage 1 staat het gebruikte IRREML script.

Voor de indeling van de Lochmann tweerijen tunnelspuit voorzien van TVI 8001 spuitdoppen in driftreductieklassen (ISO22369-1) werd de driftreductie op de gemeten afstanden en de evaluatiestroken berekend ten opzichte van de driftdepositie van de referentie bespuiting met de Munckhof dwarsstroomspuit uitgerust met Albuz ATR Lila doppen volgens:

$$
\% \text { reductie }=\frac{\left(P_{\text {driftref }}-P_{\text {techniek }}\right)}{P_{\text {driftref }}} \times 100 \%
$$

$\mathrm{P}_{\text {driftref }}=$ Percentage drift referentietechniek en dop (Munckhof dwarsstroom met Albuz ATR Lila spuitdoppen)

$\mathrm{P}_{\text {techniek }}=$ Percentage drift de Lochmann tweerijen tunnelspuit met TVI8001 spuitdoppen.

De indeling in driftreductieklasse op de strook 4,5-5,5 m vande laatste bomenrij geldt hierbij als de indeling in Drift Reducerende Techniek (DRT) klasse (TCT2017a, 2017b).

Voor het bepalen van de achtergrondfluorescentie worden blanco collectoren geanalyseerd. Het resultaat van deze metingen is een gemiddelde achtergrondfluorescentie van de blanco collectoren met een bijbehorende standaardafwijking. Bij de berekeningen van de driftdepositie (volgens bovenstaande formules) wordt het gemiddelde van de achtergrondfluorescentie gebruikt. Bij de experimenten werden zeer lage driftdeposities gemeten met fluorescentiewaarden dicht bij of zelfs onder de gemiddelde achtergrondfluorescentie. Berekende driftdeposities kunnen dan zelfs lager dan 0\% worden. De drempelwaarde, in dit rapport aangehouden, is de fluorescentiewaarde overeenkomend met twee keer de standaardafwijking van de blanco. Deze drempelwaarde is omgerekend naar driftdepositie volgens bovenstaande formules. De drempelwaarde is o.a. afhankelijk van de gemeten techniek (spuitvolume), spoelvolume bij de extractie, collectorgrootte en tankconcentratie en kan per meting (herhaling) verschillen. In de bijlagen staan de berekende waarden, ook die onder de drempelwaarde vallen. Getallen die onder de bijbehorende drempelwaarde vallen staan cursief. Als er in het rapport zelf getallen gepresenteerd worden (bv in samenvattende tabel met de afstand) waarbij de gemiddelde gemeten waarde onder de drempelwaarde komt dan wordt dat aangeven met '< drempelwaarde'. Bijvoorbeeld '<0,006'.

\subsection{Weersomstandigheden}

Tijdens de bespuitingen werden de weersomstandigheden vastgelegd door meting van de temperatuur (Pt100 op 0,5 m en $4 \mathrm{~m}$ hoogte), de luchtvochtigheid (\% RV met een Rhotronic op 1,5 m hoogte), de windrichting $\left(0^{0}=\right.$ haaks t.o.v. de bomenrijen) op $10 \mathrm{~m}$ hoogte en de windsnelheid (cupanemometers op $0,5,2,3,4$ en $10 \mathrm{~m}$ hoogte) met een tijdsinterval van 5 seconden.

De meteomast stond op 7,5 m afstand vanaf de buitenste bomenrij (zie figuren 2.1, 2.2 en 2.6). Bij elke passage van de spuit ter hoogte de meetopstellingen werd de tijd van de datalogger genoteerd. Later werd uit de verzamelde data vanuit dit passagetijdstip over 10 seconden vóór en 10 seconden ná passeertijdstip de meetwaarde gemiddeld. In bijlage 2 staan de resultaten van de metingen van de weersomstandigheden vermeld.

De metingen werden in 2018 uitgevoerd op 15 augustus, 23 augustus, 19 oktober, 13 november en 21 november. In totaal werden 10 herhalingen gemeten. Bij 2 herhalingen van de Standaard $(1+2)$ was de gemiddelde windhoek $>30^{\circ}$ van haaks. Deze metingen zijn niet verwerkt in de resultaten. De gemiddelde weersomstandigheden van de metingen staan in tabel 2.4 . 
Tabel 2.4 Gemiddelde weersomstandigheden voor de verschillende technieken tijdens de driftmetingen.

\begin{tabular}{|c|c|c|c|c|c|c|c|c|c|}
\hline \multirow[t]{2}{*}{ Techniek } & \multicolumn{2}{|c|}{$\begin{array}{c}\text { Temperatuur }\left[{ }^{\circ} \mathrm{C}\right] \\
\text { op } \\
\end{array}$} & \multirow[t]{2}{*}{$\%$ RV } & \multirow{2}{*}{$\begin{array}{l}\text { Windhoek } \\
\text { tov haaks } \\
\text { haaks }=0^{\circ}\end{array}$} & \multicolumn{5}{|c|}{ Windsnelheid [m/s] op } \\
\hline & $0,5 \mathrm{~m}$ & $4 \mathrm{~m}$ & & & $0,5 \mathrm{~m}$ & $2 \mathrm{~m}$ & $3 \mathrm{~m}$ & $4 \mathrm{~m}$ & $10 \mathrm{~m}$ \\
\hline tunnelspuit & 16.2 & 15.4 & 62 & -6 & 1,0 & 1,3 & 1,9 & 2,3 & 3,7 \\
\hline
\end{tabular}

Tijdens de driftmetingen was de gemiddelde temperatuur $14,5^{\circ} \mathrm{C}$ (op $4 \mathrm{~m}$ hoogte), de gemiddelde windhoek $-4^{\circ}$ ten opzichte van loodrecht op de bomenrij en de gemiddelde windsnelheid op $2 \mathrm{~m}$ hoogte $1,4 \mathrm{~m} / \mathrm{s}$ en op $4 \mathrm{~m}$ hoogte (ongeveer $1 \mathrm{~m}$ boven de bomen) $2,4 \mathrm{~m} / \mathrm{s}$. 


\section{Resultaten}

De resultaten van de metingen van de drift naar de grond naast het perceel zijn weergegeven in bijlage 3 en de resultaten van de drift naar de lucht zijn weergegeven in bijlage 4 .

\subsection{Drift naar de grond naast het perceel}

De gemiddelde drift per spuittechniek tijdens bespuitingen in de volblad situatie (BBCH 90/92) staan weergegeven in figuur 3.1 en in tabel 3.1.

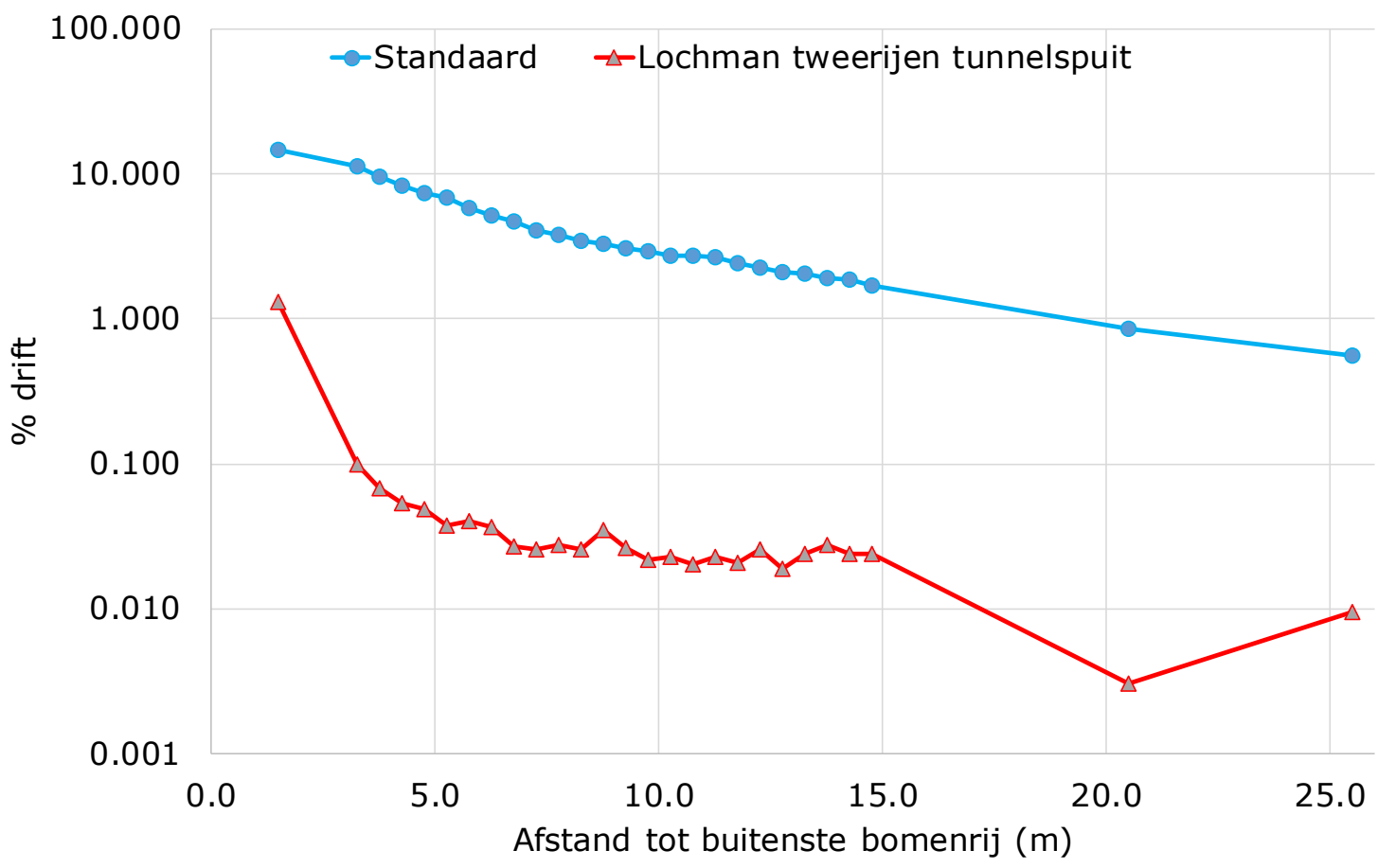

Figuur 3.1 Gemiddelde drift (\% van verspoten hoeveelheid spuitvloeistof per oppervlakte-eenheid) op verschillende afstanden vanaf het hart van de buitenste bomenrij bij bespuitingen van appelbomen in de volblad situatie (BBCH 90/92) met een standaard dwarsstroomspuit (Munckhof met ATR lila werveldoppen) en een Lochmann tweerijen tunnelspuit met TVI8001 spuitdoppen.

In figuur 3.1 en tabel 3.1 is te zien dat de standaard spuit (Munckhof dwarsstroom met ATR Lila werveldoppen) de meeste drift geeft. De Lochmann tweerijen tunnelspuit met TVI8001 spuitdoppen geeft duidelijk een lagere drift. Dit is verder uitgewerkt in tabel 3.3 voor de verschillende evaluatiestroken. 
Tabel 3.1 Gemiddelde drift (\% van verspoten hoeveelheid spuitvloeistof per oppervlakte-eenheid) op verschillende afstanden vanaf het hart van de buitenste bomenrij bij bespuitingen van appelbomen in de volblad situatie (BBCH 90/92) met een standaard dwarsstroomspuit (Munckhof met ATR lila werveldoppen) en een Lochmann tweerijen tunnelspuit met TVI8001 spuitdoppen.

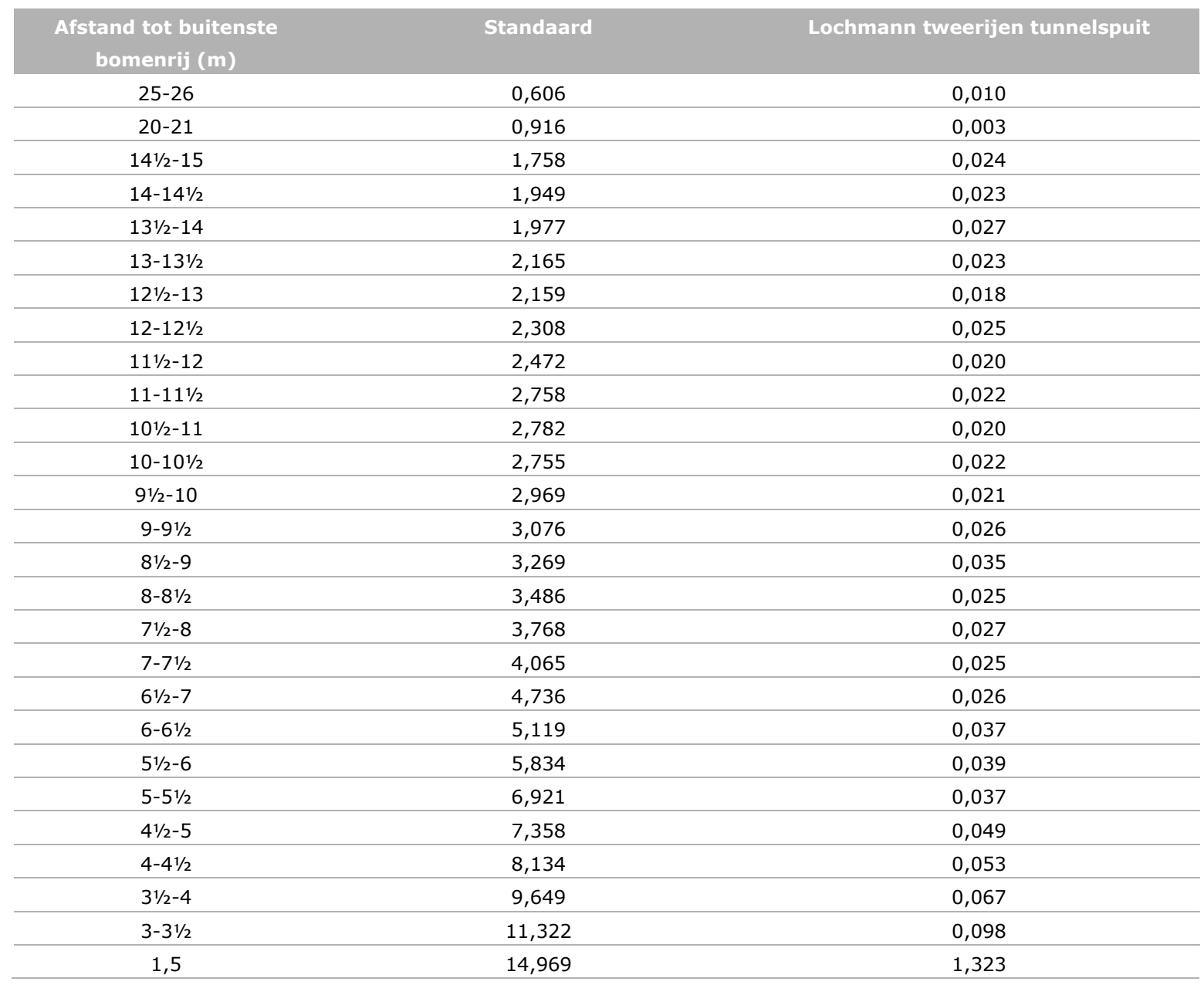

Tabel 3.2 Gemiddelde drift (\% van verspoten hoeveelheid spuitvloeistof per oppervlakte-eenheid) op de evaluatiestroken overeenkomend met teeltvrije zones van $3 m, 41 / 2 m, 6 m$ en $9 m$ bij bespuitingen van appelbomen in de volblad situatie (BBCH 90/92) met een standaard dwarsstroomspuit (Munckhof met ATR lila werveldoppen) en een Lochmann tweerijen tunnelspuit met TVI8001 spuitdoppen.

\begin{tabular}{|c|c|c|c|c|c|c|c|c|c|c|c|c|c|c|c|c|}
\hline \multirow{3}{*}{$\begin{array}{l}\text { Techniek } \\
\text { standaard }\end{array}$} & \multicolumn{16}{|c|}{ Afstand tot buitenste bomenrij ( $\mathrm{m}$ ) } \\
\hline & \multicolumn{4}{|c|}{$3 \mathrm{~m}$ teeltvrij } & \multicolumn{4}{|c|}{$41 / 2 \mathrm{~m}$ teeltvrij } & \multicolumn{4}{|c|}{$6 \mathrm{~m}$ teeltvrij } & \multicolumn{4}{|c|}{$9 \mathrm{~m}$ teeltvrij } \\
\hline & \multicolumn{2}{|c|}{ 3-7 } & \multicolumn{2}{|c|}{$41 / 2-51 / 2$} & \multicolumn{2}{|c|}{$41 / 2-81 / 2$} & \multicolumn{2}{|c|}{$6-7$} & \multicolumn{2}{|c|}{$6-10$} & \multicolumn{2}{|c|}{$71 / 2-81 / 2$} & \multicolumn{2}{|c|}{$9-13$} & \multicolumn{2}{|c|}{$101 / 2-11 \frac{1 / 2}{2}$} \\
\hline tunnelspuit & 0,05 & $\mathrm{~b}$ & 0,04 & $\mathrm{~b}$ & 0,03 & $\mathrm{~b}$ & 0,03 & $\mathrm{~b}$ & 0,03 & $\mathrm{~b}$ & 0,03 & $\mathrm{~b}$ & 0,02 & $b$ & 0,02 & $b$ \\
\hline
\end{tabular}

Verschillende letters in een kolom duiden op significante verschillen $(a<0,05)$.

Op alle stroken geeft de standaard Munckhof dwarsstroomspuit voorzien van ATR Lila werveldoppen de hoogste drift. Op de strook 41/2-51/2 m van de buitenste bomenrij, behorende bij een $3 \mathrm{~m}$ teeltvrije zone, was de drift depositie 7,14\%. De Lochmann tweerijen tunnelspuit met TVI8001 spuitdoppen (DRD90) geeft op alle stroken een significant lagere drift. Op 41/2-51/2 $\mathrm{m}$ van de buitenste bomenrij werd $0,04 \%$ drift depositie gevonden. 


\subsection{Drift naar de lucht}

De gemiddelde drift naar de lucht voor de verschillende spuittechnieken zijn weergegeven in figuur 3.2 en tabel 3.3.

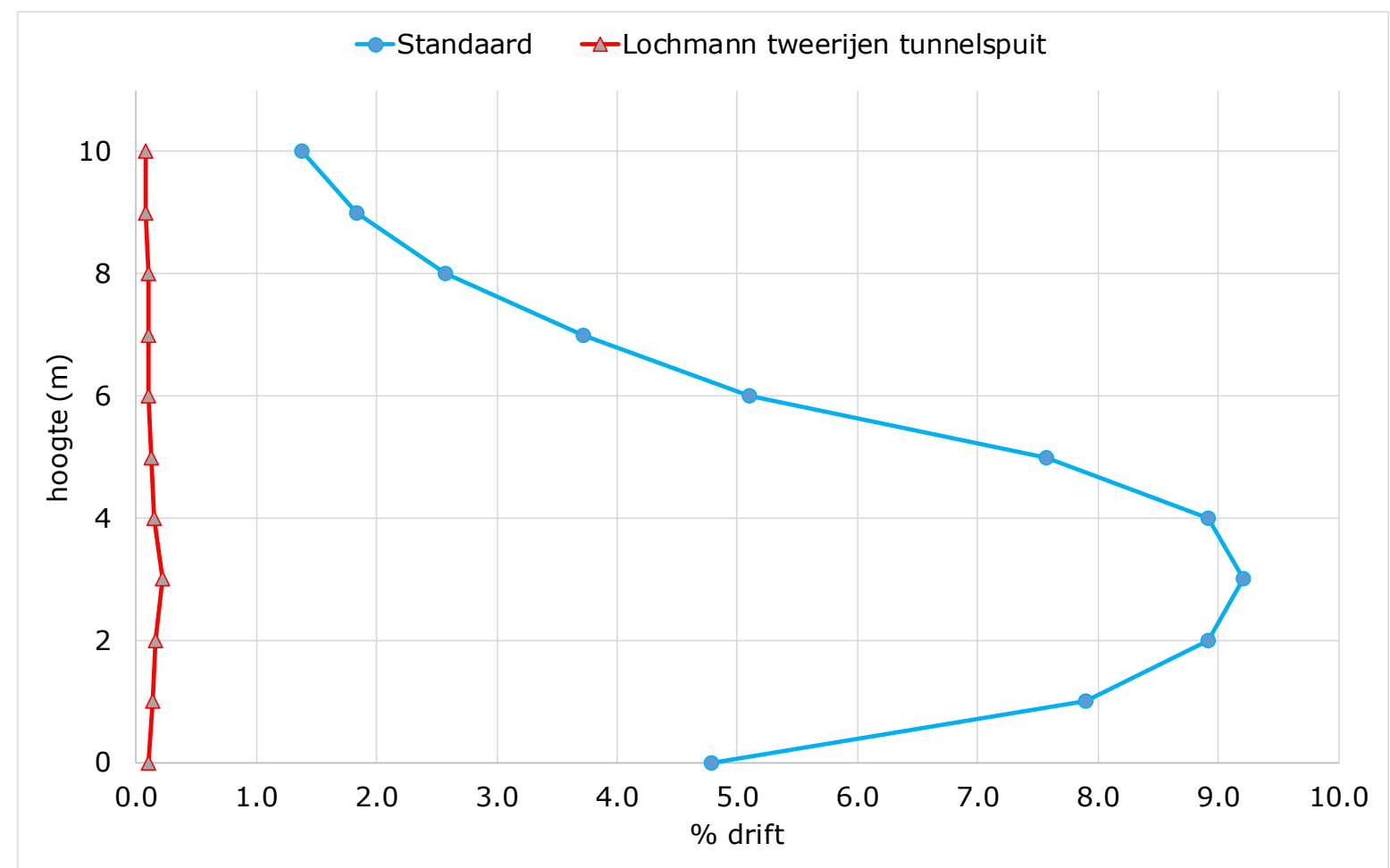

Figuur 3.2 Gemiddelde drift naar de lucht (\% van verspoten hoeveelheid spuitvloeistof per oppervlakte-eenheid) op verschillende hoogtes op $71 / 2 \mathrm{~m}$ vanaf het hart van de buitenste bomenrij bij bespuitingen van appelbomen in het volblad stadium (BBCH 90/92) met een standaard dwarsstroomspuit (Munckhof met ATR lila werveldoppen) en een Lochmann tweerijen tunnelspuit met TVI8001 spuitdoppen.

In figuur 3.2 en tabel 3.3 is te zien dat de standaard spuit (Munckhof dwarsstroom met ATR Lila werveldoppen) de meeste drift naar de lucht geeft. De Lochmann tweerijen tunnelspuit met TVI8001 spuitdoppen (DRD90) geeft duidelijk een lagere drift naar de lucht.

Bij de standaard dwarsstroomspuit met ATR Lila spuitdoppen wordt op $10 \mathrm{~m}$ hoogte nog 1,23\% drift gevonden ( $2 \%$ van totaal op 0-10 m hoogte). Bij de Lochmann tweerijen tunnelspuit wordt op $10 \mathrm{~m}$ hoogte $0,08 \%$ drift gemeten ( $6 \%$ van totaal op 0-10 m hoogte). Dit betekent dat bij beide spuittechnieken hoog genoeg gemeten is om op het hoogste meetpunt $(10 \mathrm{~m})$ meer dan $90 \%$ van de totaal opgevangen drift naar de lucht $(0-10 \mathrm{~m})$ op te vangen (ISO22866). De resultaten van de driftmetingen naar de lucht zijn verder uitgewerkt in tabel 3.4. 
Tabel 3.3 Gemiddelde drift naar de lucht (\% van verspoten hoeveelheid spuitvloeistof per oppervlakteeenheid) op verschillende hoogtes op $71 \frac{1}{2} \mathrm{~m}$ vanaf het hart van de buitenste bomenrij bij bespuitingen van appelbomen in het volblad stadium (BBCH 90/92) met een standaard dwarsstroomspuit (Munckhof met ATR lila werveldoppen) en een Lochmann tweerijen tunnelspuit met TVI8001 spuitdoppen.

\begin{tabular}{ccc} 
Hoogte $(\mathrm{m})$ & Standaard & 0,107 \\
0 & 5,017 & 0,139 \\
\hline 1 & 7,932 & 0,159 \\
\hline 2 & 8,766 & 0,214 \\
\hline 3 & 9,327 & 0,152 \\
\hline 4 & 9,420 & 0,126 \\
\hline 5 & 7,804 & 0,099 \\
\hline 6 & 4,930 & 0,101 \\
\hline 7 & 3,240 & 0,102 \\
\hline 9 & 2,300 & 0,081 \\
\hline 10 & 1,632 & 0,078 \\
\hline
\end{tabular}

Tabel 3.4 Gemiddelde drift naar de lucht (\% van verspoten hoeveelheid spuitvloeistof per oppervlakteeenheid) op verschillende hoogtes op $71 / 2 \mathrm{~m}$ vanaf het hart van de buitenste bomenrij bij bespuitingen van appelbomen in het volblad stadium (BBCH 90/92) met een standaard dwarsstroomspuit (Munckhof met ATR lila werveldoppen) en een Lochmann tweerijen tunnelspuit met TVI8001 spuitdoppen.

\begin{tabular}{|c|c|c|c|c|c|c|c|c|}
\hline \multirow{2}{*}{$\begin{array}{l}\text { Techniek } \\
\text { standaard }\end{array}$} & \multicolumn{8}{|c|}{$\%$ drift op hoogte $(\mathrm{m})$} \\
\hline & 7,76 & a & 7.87 & a & 2.67 & a & 5,60 & a \\
\hline
\end{tabular}

Verschillende letters in een kolom duiden op significante verschillen $(a<0,05)$.

Over alle hoogtes $(0-10 \mathrm{~m})$ geeft de standaard dwarsstroomspuit de hoogste drift naar de lucht. Gemiddeld over 0-10 m hoogte was de drift naar de lucht op 7,5 m van de buitenste bomenrij voor de standaard dwarsstroomspuit 5,60\%. De Lochmann tweerijen tunnelspuit met TVI8001 spuitdoppen (DRD90) geeft over 0-10 m met 0,12\% een significant lagere drift naar de lucht. 


\section{Discussie}

\section{Driftreductie}

Ten opzichte van de standaardbespuiting met de Munckhof dwarsstroomspuit gecombineerd met ATR Lila werveldoppen geeft de Lochmann tweerijen tunnelspuit met TVI8001 spuitdoppen (DRD90) bij de drift naar de grond op alle stroken een significante driftreductie tussen 99,2\%-99,4\% (tabel 4.1). Bij een teeltvrije zone van $3 \mathrm{~m}$ wordt op de strook $4 \frac{1}{2}-51 \frac{1}{2} \mathrm{~m}$ van de buitenste bomenrij een driftreductie gevonden van $99,4 \%$.

Bij de drift naar de lucht, gemiddeld over 0-10 m hoogte op 7,5 m van de buitenste bomenrij, geeft de Lochmann tweerijen tunnelspuit met TVI8001 spuitdoppen (DRD90) een significante driftreductie van $97,8 \%$.

Tabel 4.1 Gemiddelde driftreductie (\%) ten opzichte van de referentie spuit (Munckhof dwarsstroomspuit voorzien van ATR Lila werveldoppen) op de verschillende evaluatiestroken (overeenkomend met teeltvrije zones van $3 \mathrm{~m}, 41 / 2 \mathrm{~m}, 6 \mathrm{~m}$ en $9 \mathrm{~m}$ ) en naar de lucht (gemiddeld over 0-10 m hoogte) op 7,5 $\mathrm{m}$ van de buitenste bomenrij bij bespuitingen van appelbomen in het volblad stadium (BBCH 90/92) met een Lochmann tweerijen tunnelspuit met TVI8001 spuitdoppen.

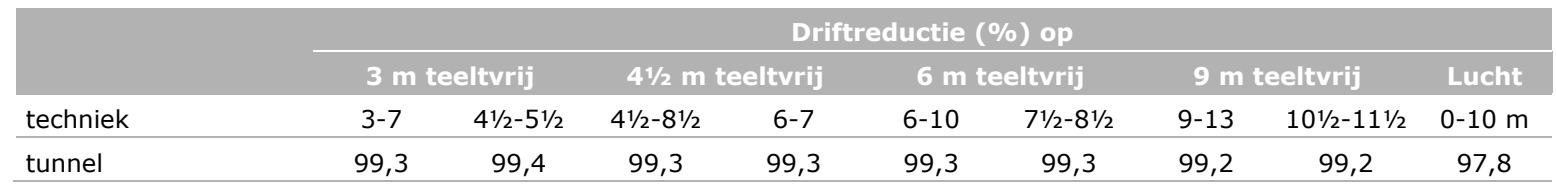




\section{$5 \quad$ Conclusie}

Bij driftmetingen tijdens bespuitingen van een appelboomgaard in het volblad stadium (BBCH 90/92) met de Lochmann tweerijen tunnelspuit met TVI8001 spuitdoppen (7 bar; DRD90) werd in vergelijking met een referentie boomgaard bespuiting bij een $3 \mathrm{~m}$ teeltvrije zone op de strook 41/2-51/2 $\mathrm{m}$ vanaf de buitenste bomenrij een driftreductie gevonden van 99,4\%. Op grond van dit resultaat kan de Lochmann tweerijen tunnelspuit met DRD90 spuitdoppen in de driftreducerende techniek klasse DRT99 ingedeeld worden.

Bij de drift naar de lucht, gemiddeld over 0-10 m hoogte op 7,5 m van de buitenste bomenrij, geeft de Lochmann tweerijen tunnelspuit met TVI8001 spuitdoppen (DRD90) een driftreductie van 97,8\%. 


\section{Literatuur}

Ctgb, 2018. Evaluation Manual for the Authorisation of Plant protection products and Biocides according to Regulation (EC) No 1107/2009 NL part Plant protection products. Chapter 6 Fate and behaviour in the environment: behaviour in surface water and sediment version 2.2 ; January 2018. http://www.ctgb.nl/

EZ, 2013. Gezonde Groei, Duurzame Oogst. Tweede nota duurzame gewasbescherming, periode 2013 tot 2023. Ministerie van Economische Zaken, Den Haag. 2013. 46p.

Gezondheidsraad, 2014. Gewasbescherming en omwonenden. Gezondheidsraad, publicatienr. 2014/02, Den Haag. 2014. 194p.

Huijsmans, J.F.M., Porskamp, H.A.J. \& Heijne, B., 1993. Orchard tunnel sprayers with reduced emission to the environment. Results of deposition and emission of new types of orchard sprayers. Proceedings A.N.P.P.-B.C.P.C. Second International Symposium on Pesticides Application, Strasbourg, 22-24 sept. 1993, BCPC, Vol. 1/2, p. 297-304.

Huijsmans, J.F.M., H.A.J. Porskamp \& J.C. van de Zande, 1997. Drift(beperking) bij de toediening van gewasbeschermingsmiddelen. Evaluatie van de drift van spuitvloeistof bij bespuitingen in de fruitteelt, de volveldsteelten en de boomteelt (stand van zaken december 1996). IMAG-DLO Rapport 97-04, IMAG, Wageningen, 38 pp.

I\&W, 2017. Regeling van de Staatssecretaris van Infrastructuur en Waterstaat, van 10 november 2017, nr. IENM/BSK-2017/254105, tot wijziging van de Activiteitenregeling in verband met de vermindering van emissies van gewasbeschermingsmiddelen in de glastuinbouw en open teelten. Staatscourant 2017 Nr. 60506.

ISO 22866, 2005. Equipment for crop protection - Methods for the field measurement of spray drift. International Standardisation Organisation, Geneva. 2005.

ISO-22369, 2006. Crop protection equipment - Drift classification of spraying equipment. Part 1. Classes. International Organization for Standardization, Geneva.

Michielsen, J.M.G.P., Wenneker, M., Zande, J.C. van de \& Heijne, B., 2007. Contribution of individual row sprayings to airborne drift spraying an apple orchard. In: E. Gil, F. Solanelles, S. Planas, J.R. Rossell \& L. Val (eds). 8th Workshop on Spray Apllication Techniques in Fruit Growing June 2005 Barcelona, Book of Abstracts, Universitat Politècnica de Catalunya, Generalitat de Catalunya, Universitat de Lleida, Barcelona, 2007. p.37-46.

Payne et al., 2006. Genstat Release 9.2.

Porskamp, H.A.J., J.M.G.P. Michielsen \& J.F.M. Huijsmans, 1994a. Emissie beperkende spuittechnieken voor de fruitteelt (1992). Onderzoek depositie en emissie van gewasbeschermingsmiddelen. IMAG-DLO rapport 94-19, IMAG-DLO, Wageningen, 43 pp.

Porskamp, H.A.J., J.M.G.P. Michielsen en J.F.M. Huijsmans, 1994b. Emissie beperkende spuittechnieken voor de fruitteelt (1993). Onderzoek emissie van gewasbeschermingsmiddelen. IMAG-DLO rapport 94-23, IMAG-DLO, Wageningen, $33 \mathrm{pp}$.

TCT, 2017a. Beoordelingssystematiek emissiereducerende maatregelen open teelt. versie 15 december 2017. [https://www.helpdeskwater.nl/onderwerpen/emissiebeheer/agrarisch/openteelt/driftreducerende/]

TCT, 2017b. Meetprotocol vaststellen driftreductie spuittechnieken [versie 1 juli 2017]. [https://www.helpdeskwater.nl/onderwerpen/emissiebeheer/agrarisch/openteelt/driftreducerende/]

TCT, 2018a. Lijst met indeling van spuittechnieken in Driftreducerende Techniek-klassen (DRTklassen) (DRT lijst). [https://www.helpdeskwater.nl/onderwerpen/emissiebeheer/agrarisch/openteelt/driftreducerende/]

TCT, 2018b. Lijst met indeling van spuitdoppen in Driftreducerende Dop-klassen (DRD-klassen) (DRDlijst). [https://www.helpdeskwater.nl/onderwerpen/emissiebeheer/agrarisch/openteelt/driftreducerende/]

VW, VROM, LNV, 2007. Wijziging van het Lozingenbesluit open teelt en veehouderij en enige andere besluiten (actualisering lozingenvoorschriften). Staatsblad 2007 143, 35p. 
Wenneker, M., J.C. van de Zande, J.M.G.P. Michielsen, H. Stallinga, P. van Dalfsen \& P. van Velde, 2018. Improvement of spray deposition in orchard spraying using a multiple row tunnel sprayer. International Advances in Pesticide Application, Aspects of Applied Biology 137, 2018. p. 101-108.

Zande, J.C. van de, M.C. Butler Ellis, M. Wenneker, P.J. Walklate \& M. Kennedy, 2014. Spray drift and bystander risk from fruit crop spraying. International Advances in Pesticide Application, Aspects of Applied Biology 122, 2014. p. 177-186.

Zande, J.C. van de, H.J. Holterman, J.F.M. Huijsmans \& M. Wenneker, 2018. Spray drift for the assessment of exposure of aquatic organisms to plant protection products in the Netherlands. Part 2: Sideways and upward sprayed fruit and tree crops. Wageningen UR, WPR Report 564, Wageningen. 2018. 


\section{Bijlage 1 Script statistische analyse}

IRREML

$[$ PRINT $=$ MOD, COM,MEAN,EFF, WALD, DEV; $\backslash$

$\mathrm{DISTR}=\mathrm{BIN} ; \mathrm{LINK}=\mathrm{LOGIT} ; \mathrm{DISP}=* ;$

RANDOM $=$ hh $*$ rij $; \backslash$

FIXED = techniek; $\backslash$

$\mathrm{PSE}=\mathrm{ALLD} ; \mathrm{CHECK}=\mathrm{YES}$; meth $=$ fisher $]$ zone; $\mathrm{NBIN}=100 ; \backslash$

RESID=Rest; FITTED =zoneFIT 


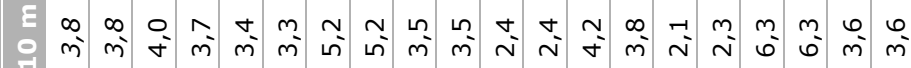

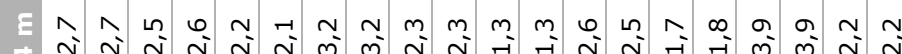

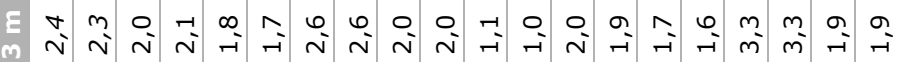

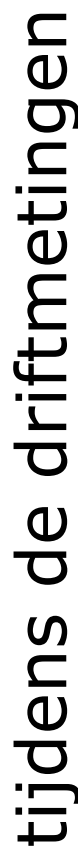

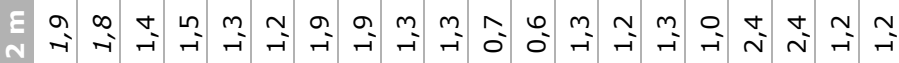

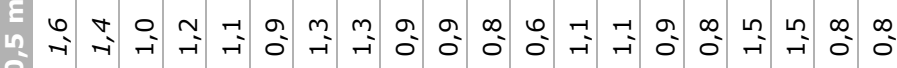

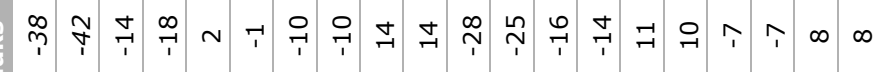

3

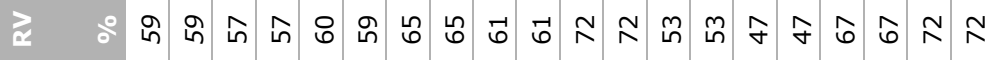

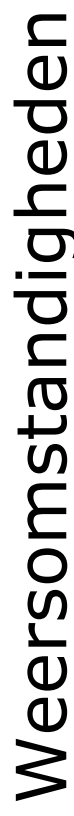

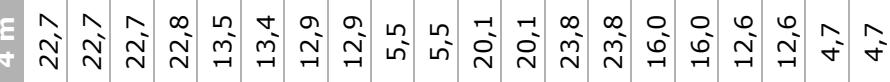

N

(1)

O

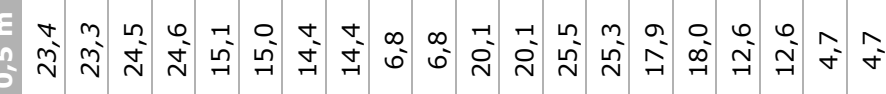

$\frac{\pi}{n}$ 


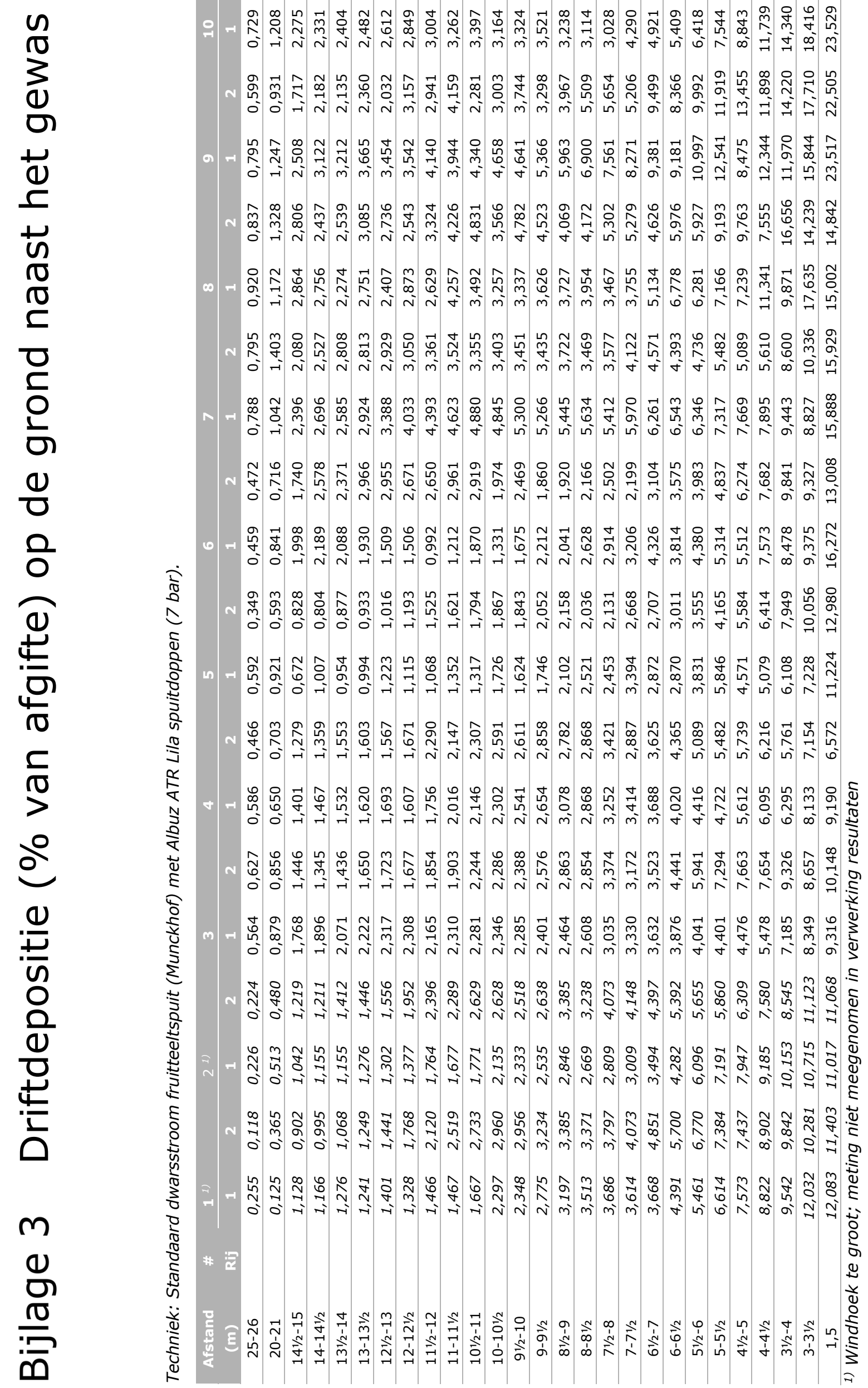




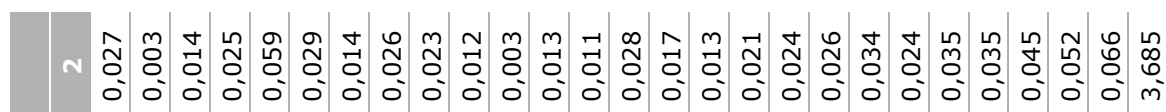

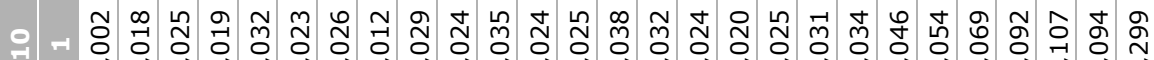

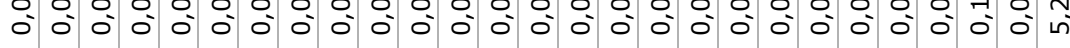

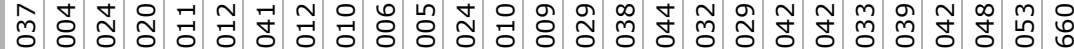

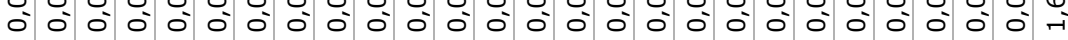

는

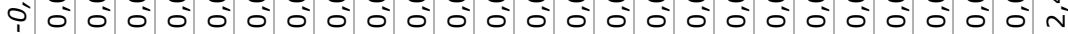

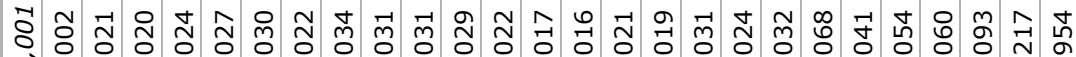

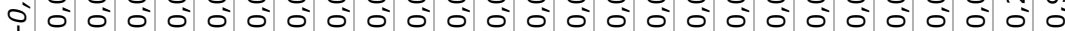

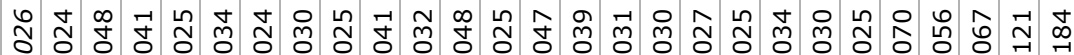

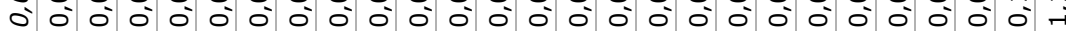

\&

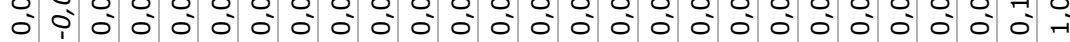

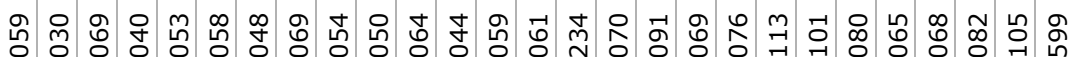

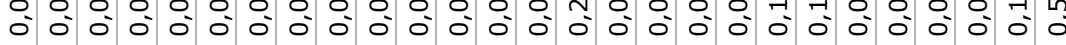

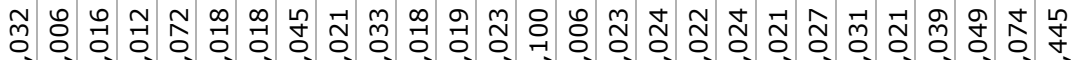

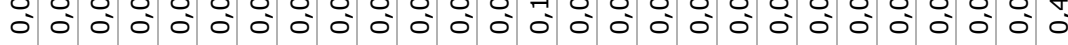

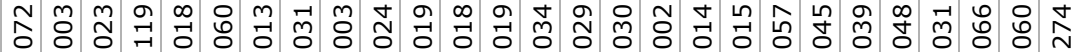

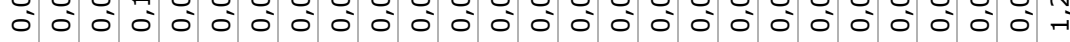

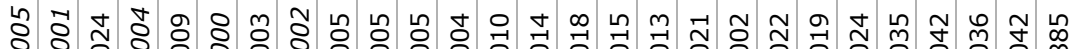

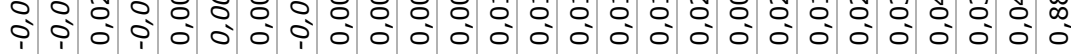

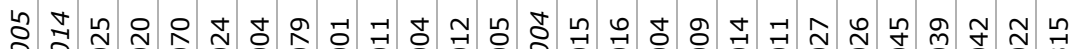

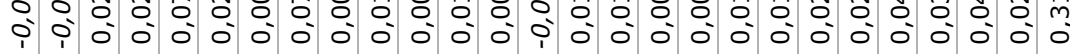

సี่

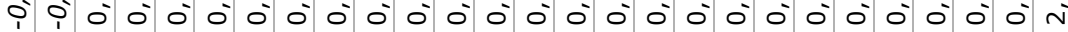

宽

¿

ฮ

\&̊̃

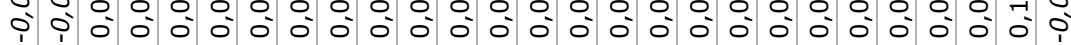

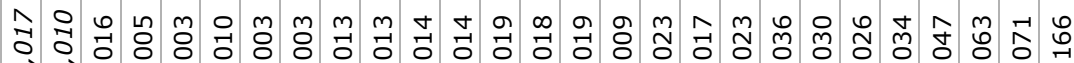

$\stackrel{8}{8}$

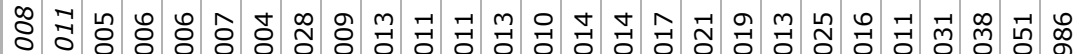

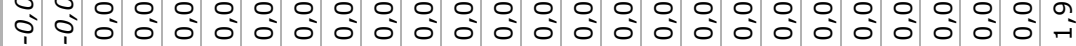

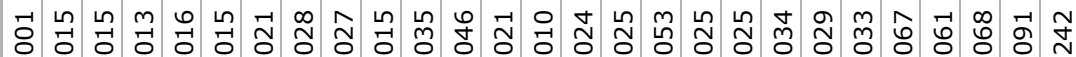

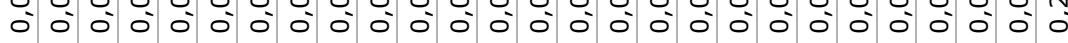

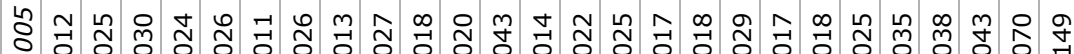

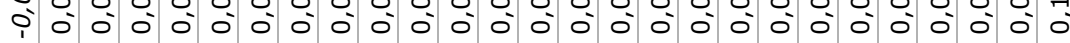

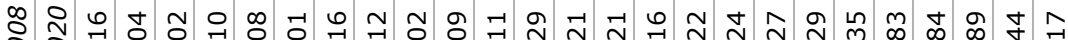
i cio

กิ

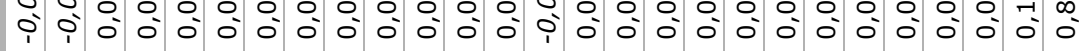




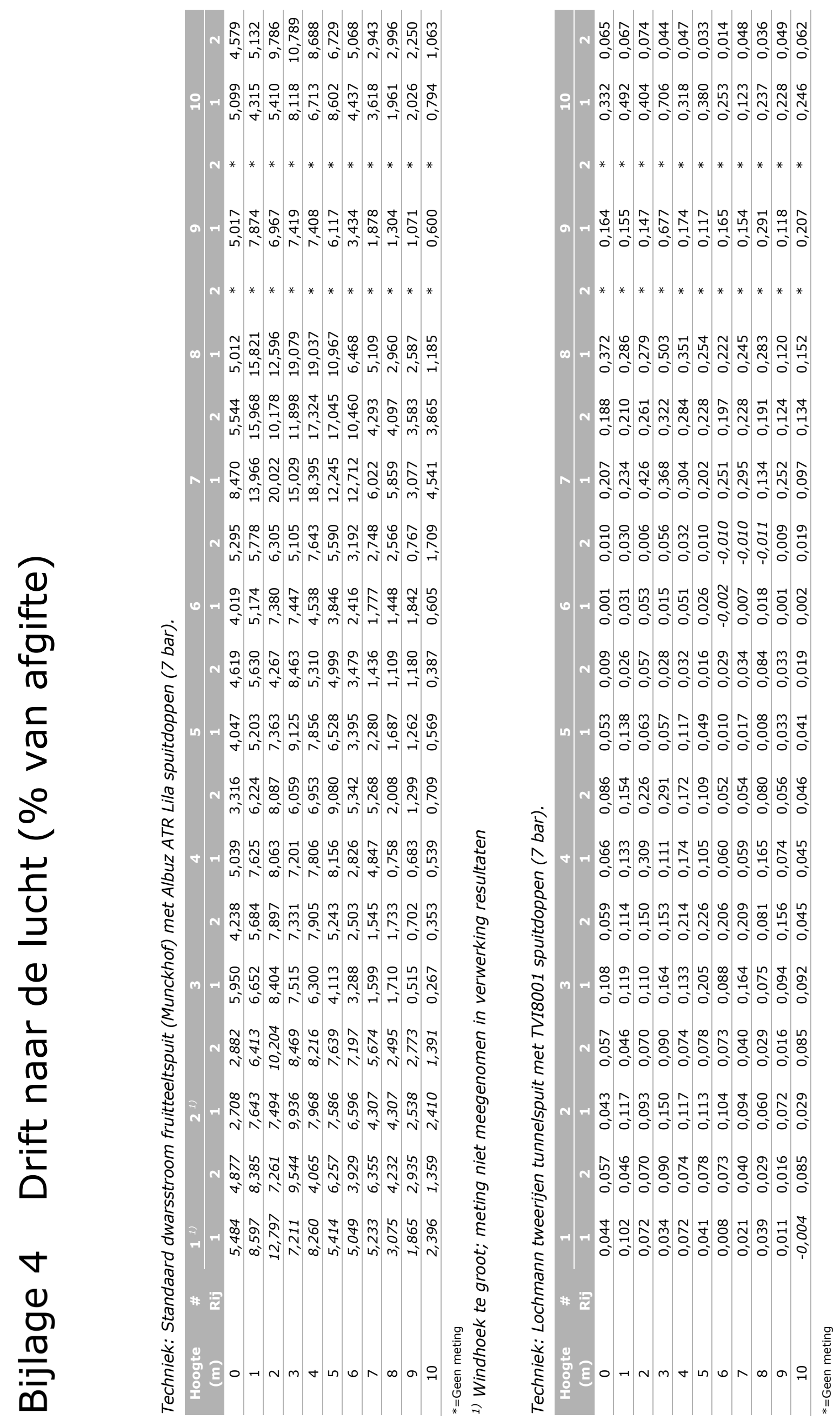




\section{Bijlage 5 Ventilator snelheid van Lochman tunnelspuit}

Om duidelijkheid te krijgen tussen het verschil in luchtopbrengst van de Lochmann tunnelspuit die in de driftmetingen gebruikt wordt en tunnelspuiten die in de praktijk rond rijden zijn vergelijkende metingen uitgevoerd. De ventilatorsnelheid van beide spuiten is gemeten bij verschillende toerentallen van de aftakas. Bij gelijk ventilator toerental hebben beide spuiten een gelijke luchtopbrengst en luchtuittreesnelheid. De uitkomst van deze vergelijkende metingen staat in tabel 1 en in figuur 1.

Tabel 1 Gemeten toerental (rpm) van de tangentiaal ventilatoren bij verschillende aftakas toerentallen (rpm) van Lochmann tunnelspuiten die in de driftmetingen gebruikt is en een praktijkmachine.

\begin{tabular}{|c|c|c|}
\hline \multirow[b]{2}{*}{ Toerental aftakas } & \multicolumn{2}{|c|}{ Toerental ventilator } \\
\hline & driftmeting & praktijk \\
\hline 300 & 1460 & 930 \\
\hline 450 & 2010 & 1410 \\
\hline 500 & 2200 & 1570 \\
\hline
\end{tabular}

De in de driftmetingen gebruikte tunnelspuit heeft een hoger ventilator toerental dan de praktijk tunnelspuit bij gelijk aftakas toerental. Hierdoor zal de luchtsnelheid / luchtopbrengst ook hoger zijn.

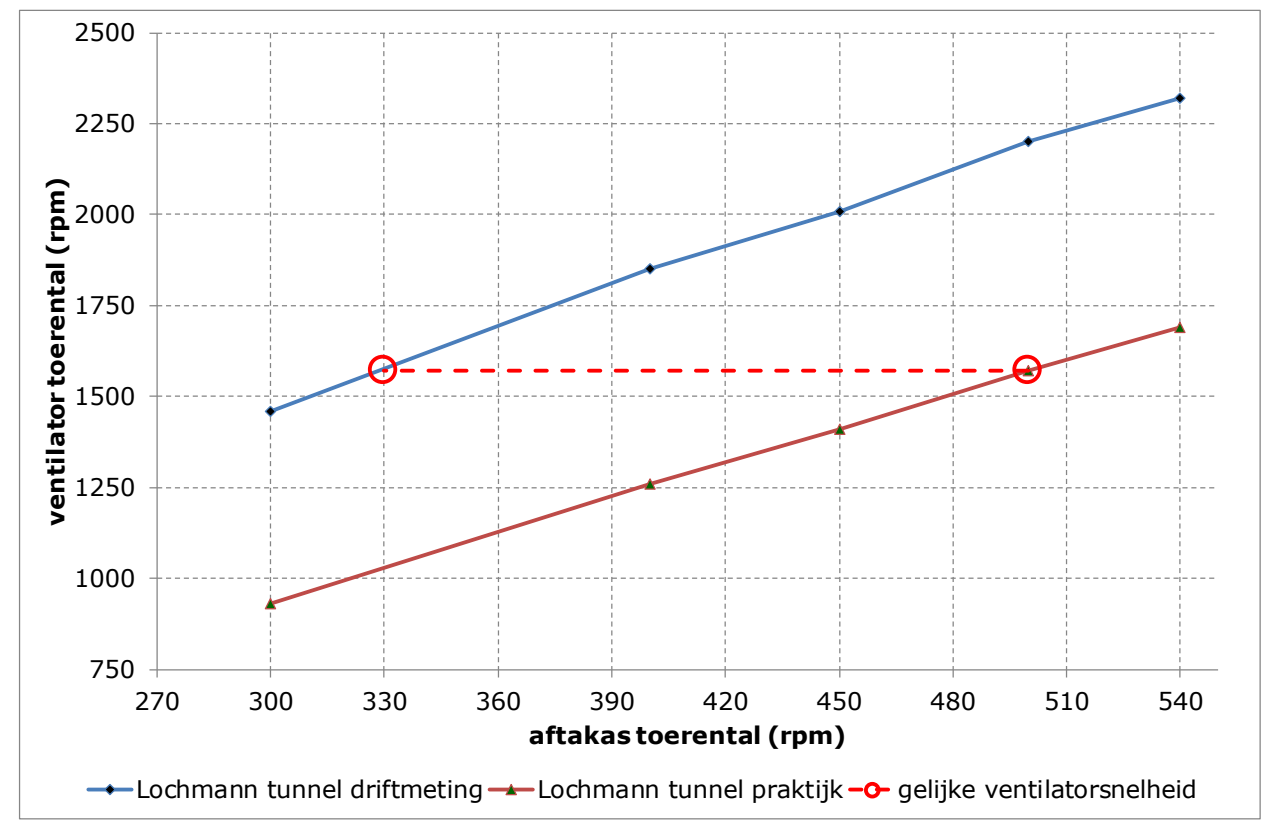

Figuur 1 Relatie tussen ventilator toerental en aftakas toerental van twee Lochmann tunnelspuiten; de spuit gebruikt in de driftmetingen en een praktijk machine.

Uit figuur 1 blijkt dat om een gelijkwaardig ventilator toerental te hebben als een tunnelspuit gebruikt in de praktijk met een aftakas toerental van 500-540 rpm, de tunnelspuit gebruikt in de driftmetingen een aftakas toerental van ongeveer $330 \mathrm{rpm}$ moet hebben. Met deze instelling (330 rpm aftakas) zijn de driftmetingen uitgevoerd. Hierdoor heeft de tunnelspuit in de driftmetingen een vergelijkbare luchtopbrengst als de tunnelspuiten in de praktijk met maximaal toerental (500-540 rpm). 
Correspondentie adres voor dit rapport: Postbus 16

6700 AA Wageningen

T 0317480700

www.wur.nl/plant-research

Rapport WPR-880
De missie van Wageningen University \& Research is 'To explore the potential of nature to improve the quality of life'. Binnen Wageningen University \& Research bundelen Wageningen University en gespecialiseerde onderzoeksinstituten van Stichting Wageningen Research hun krachten om bij te dragen aan de oplossing van belangrijke vragen in het domein van gezonde voeding en leefomgeving. Met ongeveer 30 vestigingen, 5.000 medewerkers en 10.000 studenten behoort Wageningen University \& Research wereldwijd tot de aansprekende kennisinstellingen binnen haar domein. De integrale benadering van de vraagstukken en de samenwerking tussen verschillende disciplines vormen het hart van de unieke Wageningen aanpak. 



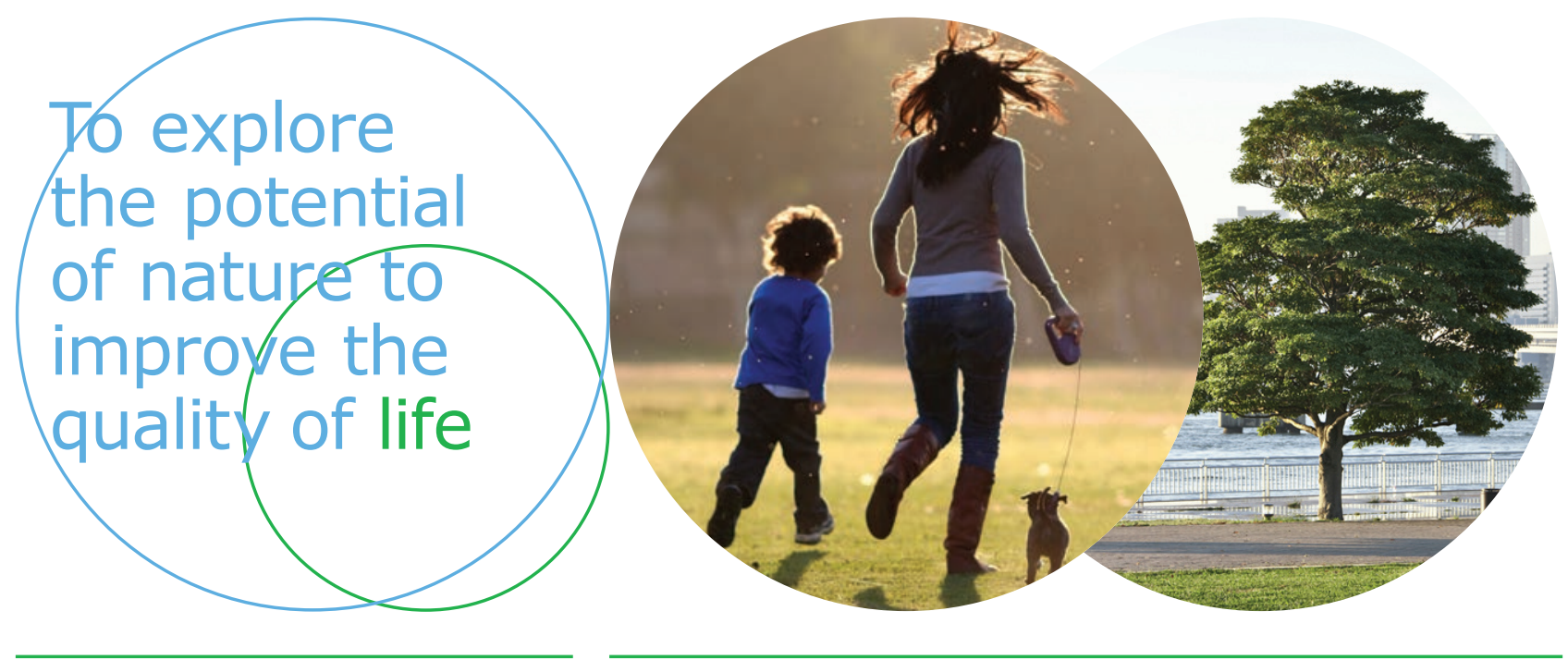

Correspondentie adres voor dit rapport: Postbus 16

6700 AA Wageningen

T 0317480700

www.wur.nl/plant-research

Rapport WPR-880
De missie van Wageningen University \& Research is 'To explore the potential of nature to improve the quality of life'. Binnen Wageningen University \& Research bundelen Wageningen University en gespecialiseerde onderzoeksinstituten van Stichting Wageningen Research hun krachten om bij te dragen aan de oplossing van belangrijke vragen in het domein van gezonde voeding en leefomgeving. Met ongeveer 30 vestigingen, 5.000 medewerkers en 10.000 studenten behoort Wageningen University \& Research wereldwijd tot de aansprekende kennisinstellingen binnen haar domein. De integrale benadering van de vraagstukken en de samenwerking tussen verschillende disciplines vormen het hart van de unieke Wageningen aanpak. 